\title{
ON STRUCTURED AND DIFFUSE SEISMICITY, STIFFNESS OF EARTHQUAKE FOCI, AND NONLINEARITY OF MAGNITUDE RECURRENCE GRAPHS
}

\author{
E. G. Bugaev \\ Scientific and engineering center for nuclear and radiation safety, \\ 107140, Moscow, Malaya Krasnoselskaya street, 2/8, bld. 5, Russia
}

\begin{abstract}
Geological, geophysical and seismogeological studies are now conducted in a more detail and thus provide for determining seismic sources with higher accuracy, from the first meters to first dozens of meters [Waldhauser, Schaff, 2008]. It is now possible to consider uncertainty ellipses of earthquake hypocenters, that are recorded in the updated Earthquake Catalogue, as surfaces of earthquake focus generators. In our article, it is accepted that a maximum horizontal size of an uncertainty ellipse corresponds to an area of a focus generator, and seismic events are thus classified into two groups, earthquakes with non-stiff and stiff foci. Criteria of such a classification are two limits of elastic strain and brittle strain in case of uniaxial $\left(3 \cdot 10^{-5}\right)$ or omnidirectional $\left(10^{-6}\right)$ compression. The criteria are established from results of analyses of parameters of seismic dislocations and earthquake foci with regard to studies of surface parameters and deformation parameters of fault zones. It is recommendable that the uniaxial compression criterion shall be applied to zones of interaction between tectonic plates, and the unilateral compression criterion shall be applied to low active (inter-plate) areas. Sample cases demonstrate the use of data sets on non-stiff and stiff foci for separate evaluation of magnitude reoccurrence curves, analyses of structured and dissipated seismicity, review of the physical nature of nonlinearity of recurrence curves and conditions of preparation of strong earthquakes. Changes of parameters of the recurrence curves with changes of data collection square areas are considered. Reviewed are changes of parameters of the recurrence curves during preparation for the Japan major earthquake of 11 March 2011 prior to and after the major shock. It is emphasized that it is important to conduct even more detailed geological and geophysical studies and to improve precision and sensitivity of local seismological monitoring networks in zones of nuclear stations and other hazardous facilities. It is noted that a list of parameters recorded in earthquake catalogues needs to be extended. Based on the above, it will be possible to ensure proper monitoring of stability of the seismic process during construction, operations and decommissioning of nuclear stations.
\end{abstract}

Key words: ellipse of uncertainty; the earthquake source: rigid, slow, structured, diffuse; recurrence curve magnitudes: linear and nonlinear.

Recommended by S.I. Sherman 1 September 2011.

Citation: Bugaev E.G. On structured and diffuse seismicity, stiffness of earthquake foci, and nonlinearity of magnitude recurrence graphs // Geodynamics \& Tectonophysics. 2011. V. 2. № 3. P. 244-265. doi: 10.5800/GT2011-2-3-0045.

\section{О СТРУКТУРИРОВАННОЙ И РАССЕЯННОЙ СЕЙСМИЧНОСТИ, ЖЕСТКОСТИ ОЧАГОВ ЗЕМЛЕТРЯСЕНИЙ И НЕЛИНЕЙНОСТИ ГРАФИКОВ ПОВТОРЯЕМОСТИ МАГНИТУД}

\author{
Е. Г. Бугаев
}

Научно-технический центр по ядерной и радиационной безопасности, 107140, Москва, ул. Малая Красносельская, 2/8, строение 5, Россия 
Аннотация: Повышение детальности геолого-геофизических и сейсмологических исследований позволило с высокой точностью - от первых метров до первых десятков метров - определять положение сейсмических излучателей [Waldhauser, Schaff, 2008] и послужило основанием для рассмотрения параметров эллипса неопределенности определения гипоцентра, включенных в уточненный каталог сейсмических событий, в качестве поверхности излучателя очага землетрясения. В работе принято соответствие максимального горизонтального размера эллипса неопределенности и размера области излучателя очага. Это позволило разделить сейсмические события на вялые и жесткие землетрясения. В качестве критериев приняты два предела упругого деформирования и хрупкого разрушения при одноосном $\left(3 \cdot 10^{-5}\right)$ или всестороннем $\left(10^{-6}\right)$ сжатии. Критерии установлены на основании анализа параметров сейсмодислокаций и очагов землетрясений с учетом результатов изучения прочностных и деформационных характеристик зон разломов. Для зон интенсивного взаимодействия тектонических плит и слабоактивных (межплитовых) территорий рекомендовано использовать критерии, принятые для одноосного и всестороннего сжатия соответственно. Приведены примеры использования выборок вялых и жестких очагов при раздельной оценке графиков повторяемости магнитуд, анализе структурированной и рассеянной сейсмичности, рассмотрении физической природы нелинейности графиков повторяемости и условий подготовки сильных событий. Рассмотрено изменение параметров графиков повторяемости в зависимости от размеров площади сбора информации, а также параметров графиков повторяемости при подготовке главного события 11 марта 2011 г. в Японии и после него. Отмечена актуальность повышения детальности геолого-геофизических исследований, точности и чувствительности локальных сейсмологических сетей наблюдений в районах размещения атомных станций и других опасных объектов и расширения круга параметров, включаемых в каталоги землетрясений, для контроля стабильности сейсмического процесса при строительстве, эксплуатации и выводе атомной станции из эксплуатации.

Ключевые слова: эллипс неопределенности; очаг землетрясения: жесткий, вялый, структурированный, рассеянный; график повторяемости магнитуд: линейный, нелинейный.

\section{1. ВВЕДЕНИЕ}

При Общем сейсмическом районировании территории Российской Федерации (ОСР-97) оценка сейсмической опасности выполняется с учетом влияния структурированной и рассеянной сейсмичности. В качестве источников сейсмических воздействий приняты отдельные очаги и линеаменты, отражающие структурируемую сейсмичность, и домены (или сейсмотектонические провинции), характеризующиеся рассеянной сейсмичностью. Очаги и линеаменты имеют более или менее надежную основу для оценки параметров сейсмического режима и оценки максимальной магнитуды $\left(\mathrm{M}_{\text {мах }}\right)$, в то время как домены содержат чаще всего ограниченное число сейсмических событий, структурная приуроченность которых явно не выражена. Последнее связано с тем, что детальность ОСР-97 не позволяет выявить все структуры, к которым могли быть приурочены известные землетрясения. Положение осложняется тем, что существующие сейсмологические сети не обеспечивают соответствующую точность определения эпицентров, достаточную для уверенной привязки эпицентра к конкретной тектонической структуре. В связи с этим, надежность и достоверность выделения доменов и определения параметров сейсмического режима представляются весьма низкими. Тем не менее для каждой региональной зоны возникновения очагов землетрясений (зоны ВОЗ), включая домены, приняты $\mathrm{M}_{\text {мах }}$ и параметры сейсмического режима, на основании которых с использованием гипотезы рассеянной сейсмичности оценивается средняя равновероятная сейсмическая опасность для всей территории домена. Принципиальной особенностью оценки сейсмической опасности при ОСР-97 является учет нелинейности региональных графиков повторяемости, что, как правило, приводит к увеличению вероятности проявления сильных землетрясений и повышению сейсмической опасности, при этом физическая природа нелинейности региональных графиков повторяемости при ОСР-97 не рассмотрена [Уломов, Шумилина, 1999]. Следует отметить, что изучению физической природы нелинейности региональных графиков повторяемости и их учету при оценке $\mathrm{M}_{\text {мах посвящена рабо- }}$ та [Востриков, 1994].

Достоверность и надежность результатов ОСР-97 применительно к обоснованию безопасности атомных станций (АС) ставятся под сомнение из-за недостаточной детальности геолого-геофизической, геодинамической и сейсмологической основы ОСР-97 для обоснования однородности домена, отсутствия четких критериев разделения очагов на структурированные и рассеянные, принятия $\mathrm{M}_{\text {мах }}$ и оценки параметров региональных графиков повторяемости. Это определяет актуальность проведения специальных сейсмологических исследований для уточнения результатов ОСР-97 и совершенствования методов обоснования геодинамических и сейсмотектонических условий размещения АС и методологии оценки сейсмической опасности. 


\section{2. КРАТКИЙ ОБЗОР ПРОБЛЕМЫ УТОЧНЕНИЯ РЕЗУЛЬТАТОВ ОСР-97}

Отмеченные выше основные проблемы ОСР-97 не новы. Для подразделения очагов землетрясений на структурированные и рассеянные широко использовались методы кластерного анализа на основе «индекса Моришиты», или метода ближайшего соседа [Шебалин, 1997; Арефьев, 2003]. Основная проблема этих подходов состоит в том, что они основаны на формальном признаке близости событий и не учитывают физическую природу очагов. Недостаточная изученность структурно-тектонических и геодинамических условий территорий размещения АС и низкая точность определения координат гипоцентров также затрудняют решение проблемы обоснования безопасного размещения АС. Необходимость регистрации микроземлетрясений, повышения точности определения положения очагов и картирования активизированных локальных структур, не установленных геофизическими и геологическими методами, по результатам детальных сейсмологических наблюдений отмечалась в работе [Шебалин, 1997]. Здесь же отмечалось, что использование применительно к слабоактивным территориям гипотезы рассеянной сейсмичности при вероятностной оценке редких событий с повторяемостью 1 раз в 10000 лет может приводить к необходимости учета очень высоких магнитуд - до 8.0 и выше. Это касается оценки максимального сейсмического потенциала сильнейших внутриплитовых землетрясений 1811-1812 гг. с $\mathrm{M}_{\text {наб }}=8.1$ в Нью-Мадридской зоне, которые долгое время считались «экзотическими», произошедшими в совершенно «неподходящих» местах, где крупные структуры в земной коре не выявлены [Шебалин, 1997]. Однако анализ результатов детальных исследований показал, что Нью-Мадридская зона приурочена к зоне пересечения крупных тектонических структур XV порядка и выше (согласно классификации М.А. Садовского и М.В. Пиотровского А. Кайе) и характеризуется относительно высокой геодинамической и сейсмической активностью [Грачев, 1994; Chiu, 1990; Gomberg, 1993].

В работе [Шебалин, 1997] отмечено существование жестких и вялых очагов и актуальность установления критериев их разделения. Впервые в качестве критерия относительной жесткости (или прочностных свойств) очагов в работе [Прозоров, Хадсон, 1974] была использована разность магнитуд, установленных с учетом поверхностных и объемных волн («крипекс» Прозорова). Было принято, что чем больше магнитуда объемных волн, тем меньше «крипекс» и тем больше «жесткость» очага и меньше вклад крипа в очаговый процесс. Однако из-за отсутствия четкого физического обоснования принятого критерия и одновременных определений магнитуд по объемным и поверхностным волнам в локальных каталогах землетрясений использование «крипекса» не нашло практического примене- ния при проведении сейсмологических исследований для размещения АC.

Детальные геодинамические и сейсмологические исследования районов размещения АС на территории Восточно-Европейской платформы показали, что территории доменов неоднородны и могут быть подразделены на квазиоднородные тектонические блоки, разделенные геодинамическими зонами соответствующих порядков. Установлено, что очаги землетрясений, как правило, не рассеяны, а структурированы приурочены к геодинамическим зонам различных порядков: более сильные события приурочены к более крупным зонам, а относительно слабые проявляются и в мелких внутриблоковых нарушениях и даже внутри микроблоков, выделение в пределах которых мелких нарушений не было обеспечено принятой детальностью исследований. В свою очередь, привязка очагов к конкретным зонам нарушений осложняется также низкой точностью определения положения эпицентров (порядка 5 км). Таким образом, отсутствие детальных структурных карт, низкая точность определения положения гипоцентров и традиционный состав информации, включаемой в каталоги землетрясений, попрежнему затрудняют расширение задач изучения пространственных и временных закономерностей сейсмического процесса, структурной приуроченности очагов и физической природы нелинейности графиков повторяемости.

\section{3. НОВЫЙ МЕТОД АНАЛИЗА ДАННЫХ УТОЧНЕННЫХ КАТАЛОГОВ}

Проведение детальных геолого-геофизических исследований позволило разработать 3-D модель распределения скоростей распространения сейсмических волн. Наличие 3-D модели и достаточного количества сейсмических станций дало основание определять положение сейсмических источников с точностью от первых метров до первых десятков метров в горизонтальной плоскости и не больше 100 м по глубине. Это позволило переопределить координаты гипоцентров землетрясений, которые были зарегистрированы не менее чем шестью станциями, и дополнительно включить в уточненный каталог [http://www.ncedc.org] параметры эллипса неопределенности положения очага (размеры двух горизонтальных и одной вертикальной оси) [Waldhauser, Schaff, 2008]. В работе [Kocharyan et al., 2010] данные уточненного каталога [Waldhauser, Schaff, 2008] впервые были использованы для изучения детальной структуры фрагмента зоны разлома Калаверс, входящего в систему разломов зоны СанАндреас. Авторами [Kocharyan et al., 2010] было рассмотрено «поведение» зоны разлома по простиранию и по глубине и установлено, что 75 \% сейсмических событий приходится на узкую зону влияния разлома и лишь 25 \% на рассеянную (диффузную) сейсмичность. 
Поставлена задача дальнейшего изучения пространственно-временных закономерностей изменения сейсмического процесса, а также отмечена необходимость организации полигона для детальных сейсмологических наблюдений.

Высокая точность определения положения сейсмических источников [Waldhauser, Schaff, 2008] дает основание также рассматривать эллипс неопределенности не в качестве характеристики ошибки определения положения гипоцентра, а в качестве поверхности излучателя сейсмических волн, т.е. очага землетрясения, придав ему определенный физический смысл. Такое предположение позволяет в первом приближении принять максимальный горизонтальный размер эллипса неопределенности в качестве максимального горизонтального размера очага. Анализ данных уточненного каталога землетрясений показал, что горизонтальные размеры эллипса неопределенности, как правило, на порядок и больше превышают точность определения положения источника сейсмических сигналов и достигают сотен метров и первых километров. Такие величины параметров эллипса неопределенности сопоставимы с размером очаговой зоны, определяемым для рассматриваемого диапазона магнитуд согласно работе [Аптикаев, 2001]. Это является достаточным основанием для принятия допущения о соответствии максимального горизонтального размера эллипса неопределенности и размера очага. Достоверность принятого допущения в геометрическом плане также может быть обоснована расчетом [Касахара, 1985; Соболев, Пономарев, 2003]. Принятое допущение позволяет, в свою очередь, на основании данных о деформационных характеристиках среды в очагах землетрясений поставить задачу подразделения регистрируемых сейсмических событий тектонического происхождения на жесткие и вялые землетрясения.

\section{4. ДЕФОРМАЦИОННЫЕ ХАРАКТЕРИСТИКИ СРЕДЫ В ОЧАГАХ ЗЕМЛЕТРЯСЕНИЙ}

Для установления деформационных характеристик среды, разработки критериев выделения потенциальных зон ВОЗ и оценки $\mathrm{M}_{\text {мах }}$ был выполнен анализ параметров сейсмогенных дислокаций, очагов землетрясений и импульсов релаксации - микроземлетрясений. Для реализации этой работы использованы сейсмические события, которые произошли в различных геодинамических условиях и были приурочены к геологическим структурам самых разных регионов [Ваков, 1992; Никонов, 1977, 1987; Раутиан, 1988; Хромовских, 1995; и др.].

Анализ наблюденных данных о параметрах сейсмогенных дислокаций и инструментальных данных о параметрах очагов землетрясений позволил с учетом прочностных характеристик зон разломов различных порядков выявить предельные параметры очагов в за- висимости от их размера, условий нагружения и характера (типа) разрушения среды. С учетом основных положений модели твердого тела со структурой установлена связь этих параметров с параметрами локальных зон ВОЗ. Под локальными зонами ВОЗ на платформе понимаются активные в четвертичное время геодинамические зоны.

Анализировались данные о параметрах землетрясений с магнитудой М от 3.6 до 8.6, в очаговых зонах которых установлено изменение длины сейсмогенного разрыва от 10 до почти 1000 км, амплитуды подвижки от 0.01 до $\sim 30.00$ м и соответственно деформации в очаге в диапазоне от $10^{-8}$ до почти $10^{-3}$. Величина деформации среды с учетом общепринятой модели центральной симметрии очага определялась как отношение амплитуды подвижки к длине сейсмогенного разрыва.

Основной задачей анализа параметров сейсмогенных дислокаций является определение возможного диапазона взаимного изменения магнитуды, длины, амплитуды подвижки и деформации первичных (сейсмогенных) дислокаций в зависимости от длины разрыва в очаге. Анализировались взаимные распределения десятичных логарифмов амплитуд, длин разрыва и деформаций в очагах землетрясений.

В отличие от традиционных подходов, ориентированных на проведение регрессионного анализа и выявление парных корреляций рассматриваемых параметров, в данной работе установлены пределы изменения этих параметров для условий упругого деформирования и хрупкого («хр») или хрупко-пластического («хрпл») разрушения в условиях всестороннего сжатия («вс») и одноосного сжатия («ос»). В скобках приведены индексы «хр», «хр-пл», «вс» и «ос», которые в дальнейшем используются в соответствующих соотношениях, характеризующих пределы изменения рассматриваемых параметров в разных условиях формирования и проявления очагов землетрясений.

\section{1. ЗАВИСИМОСТЬ ПРЕДЕЛЬНОЙ ДЕФОРМАЦИИ ОТ ДЛИНЫ РАЗРЫВА И МАГНИТУДЫ}

Данные о рассеянии величины деформации в зависимости от длины разрыва в очаге и магнитуды землетрясения представлены на рис. 1 и 2 соответственно. Визуальный анализ этих данных позволил установить два предела упругого деформирования и хрупкого разрушения.

Первый предел соответствует условиям упругого деформирования и хрупкого разрушения при всестороннем сжатии и контролирует минимальные значения остаточных деформаций в очаге, величина которых не зависит от магнитуды и длины разрыва в очаге [Бугаев, Спунгин, 2007]:

$$
\mathrm{E}_{\text {хр вс }}=1.8 \cdot 10^{-6}\left(\sim 10^{-6}\right) \text { или } \lg \mathrm{E}_{\text {хр вс }} \approx-5.5(\sim-6),
$$


где $\mathrm{E}_{\text {хр вс }}$ - верхний предел упругого деформирования среды в очаге землетрясения в условиях всестороннего сжатия.

Второй предел упругого деформирования и хрупкого разрушения среды в условиях одноосного сжатия ограничивает сверху величины деформаций, установленные для гладких очагов, и также не зависит ни от магнитуды, ни от длины разрыва в очаге землетрясения:

$$
\mathrm{E}_{\text {хр ос }}=3.16 \cdot 10^{-5} \text { или } \lg \mathrm{E}_{\mathrm{xp} \mathrm{ос}}=-4.5,
$$

где $\mathrm{E}_{\mathrm{xp}}$ ос - верхний предел упругого деформирования среды в очаге землетрясения при одноосном сжатии.

Область рассеяния величин деформаций визуально может быть ограничена сверху соотношением, которое отражает характер снижения предельной деформации с увеличением магнитуды и длины разрыва в очаге землетрясения:

$$
\lg \mathrm{E}_{\text {хр-пл ос }}=-0.5 \lg \mathrm{L}_{0}-3.0 \text {, }
$$

где $\mathrm{E}_{\mathrm{xp} \mathrm{oc}}$ - предельная деформация в очаге землетрясения; $\mathrm{L}_{0}$ - длина разрыва в очаге землетрясения, км.

Уравнение (3) показывает зависимость предельной величины хрупко-пластической деформации в очагах землетрясений от длины разрыва.

При увеличении длины разрыва в очаге в $k$ раз величина предельной деформации в очаге землетрясения уменьшается в $\sqrt{k_{i}}$ раз.

Точка пересечения прямых, определяемых соотношениями (2) и (3), позволяет оценить предельную длину разрыва в очаге $\mathrm{L}_{\text {oc }} \approx 1000$ км (рис. 1) и предельную магнитуду $\mathrm{M}_{\mathrm{oc}} \approx 8.5$ (рис. 2) для условий одноосного сжатия. При таких сейсмических событиях неупругие деформации, по-видимому, охватывают земную кору и верхнюю мантию.

На рис. 1 прямая, определяемая соотношением (4), ограничивает снизу область рассеяния основной массы данных о деформациях в сейсмогенных дислокациях и субочагах и отражает величину хрупко-пластических деформаций в условиях всестороннего сжатия в зависимости от длины разрыва $\mathrm{L}_{o}$ в очаге в виде:

$$
\lg \mathrm{E}_{\text {хр-пл вс }}=-0.5 \lg \mathrm{L}_{0}-4.5 \text {, }
$$

где $\mathrm{E}_{\text {хр-пл вс }}$ - минимальные значения хрупко-пластических деформаций в очагах землетрясений в условиях всестороннего сжатия; $\mathrm{L}_{0}$ - длина разрыва в очаге, км.

Точка пересечения линий, определяемых соотношениями (1) и (4), позволяет оценить эффективные предельные параметры очага землетрясения в земной

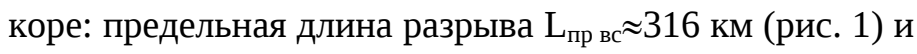

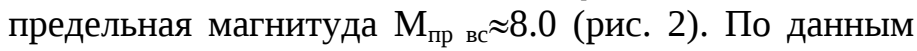
работ [Стром, 1993; Strom, Nikonov, 1997] эта величина не превышает 7.8 .
Аналогичные зависимости предельных величин хрупко-пластических деформаций в очагах землетрясений от магнитуды представлены на рисунке 2 и имеют вид:

$$
\lg \mathrm{E}_{\text {хр-пл вс }}=-0.5 \mathrm{M}-1.75 \text {, }
$$

где $\mathrm{E}_{\text {хр-пл вс }}$ - нижний предел хрупко-пластических деформаций;

$$
\lg \mathrm{E}_{\text {хр-пл ос }}=-0.5 \mathrm{M}-0.25 \text {, }
$$

где $\mathrm{E}_{\text {хр-пл ос }}$ - верхний предел хрупко-пластических деформаций.

На основании анализа параметров сейсмогенных дислокаций установлены: пределы деформаций при упругом деформировании и хрупком разрушении

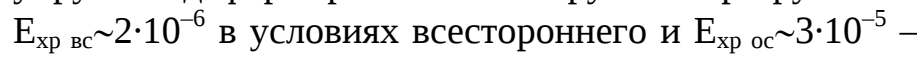
одноосного сжатия, которые не зависят от магнитуды и длины разрыва в очаге, а также устойчивое уменьшение предельных хрупко-пластических деформаций $\mathrm{E}_{\mathrm{xp-пл} \mathrm{вс}}$ и $\mathrm{E}_{\text {хр-пл ос }}$ с увеличением длины разрыва $\mathrm{L}_{\mathrm{p}}$ в очаге и магнитуды М землетрясения.

При увеличении длины разрыва в очаге в $k$ раз ве-

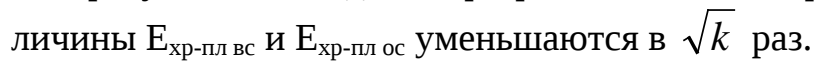

Отдельного внимания заслуживают особенности проявления деформаций гладких очагов и субочагов, для которых характерно увеличение деформации с уменьшением размера очага и рост магнитуды с увеличением деформации. Эти закономерности определяют имеющее место увеличение деформаций и магнитуд на локальных зацепах, приводящих к упрочнению среды и увеличению рассеяния рассматриваемых параметров по мере уменьшения размера очага.

\section{2. ЗАВИСИМОСТЬ МАГНИТУДЫ ОТ ДЛИНЫ РАЗРЫВА В ОЧАГЕ}

Область рассеяния магнитуд наблюденных землетрясений в зависимости от логарифма длины разрыва в очаге представлена на рис. За. При одноосном сжатии имеет место устойчивая зависимость минимальной магнитуды от максимальной длины разрыва в субочагах (жестких очагах):

$$
\mathrm{M}_{\text {мин хр-пл ос }}=1.5 \lg \mathrm{L}_{\text {мах }}+4.0 \text {, }
$$

где $\mathrm{M}_{\text {мин хр-пл ос }}$ - минимальная магнитуда субочага (или максимальная магнитуда гладкого очага); $\mathrm{L}_{\text {мах }}$ - максимальная длина разрыва в субочаге (или минимальная длина разрыва гладкого очага), км.

Таким образом, соотношение (7a) контролирует нижний предел проявления субочагов (жестких очагов) и верхний предел проявления гладких (вялых) очагов землетрясений.

$\mathrm{K}$ сейсмодислокации длиной $\mathrm{L}_{\text {мах }}$ могут быть при-

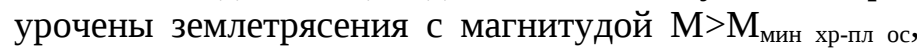




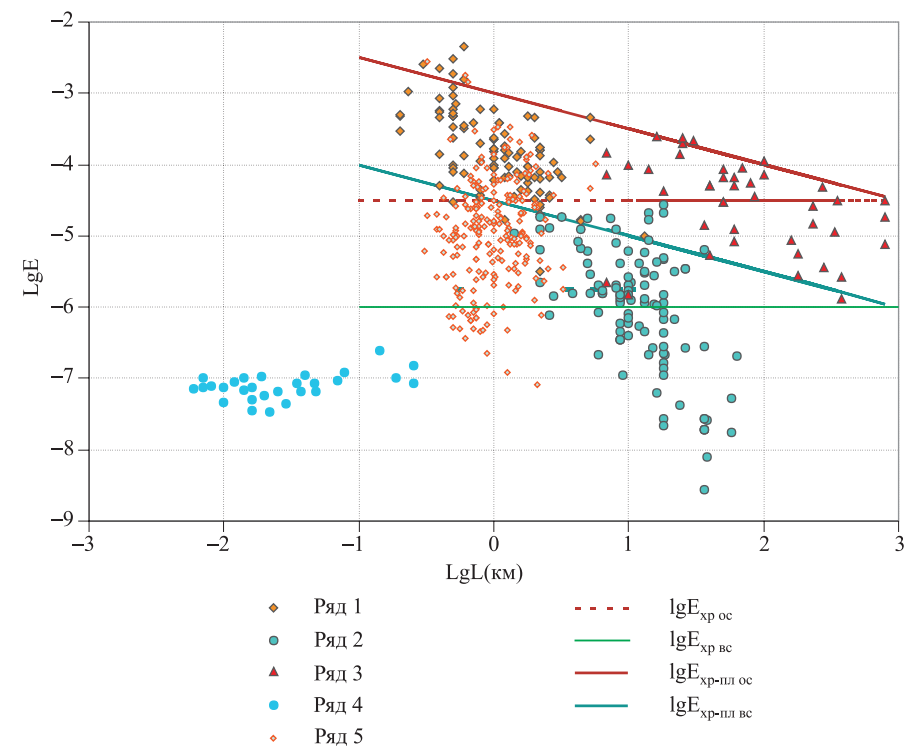

Рис. 1. Зависимость десятичных логарифмов прогнозных предельных деформаций (lgE) в очаге при хрупком (хр) и хрупко-пластичном (хр-пл) разрушении при всестороннем (вс) и одноосном (ос) сжатии и наблюденных деформаций в очагах от десятичного логарифма длины разрыва $(\operatorname{lgL}($ км)) в очаге. Ряд 1 - субочаги (или жесткие очаги) (по данным Т.Г. Раутиан); Ряд 2 - гладкие (или вялые) очаги (по данным Т.Г. Раутиан); Ряд 3 - сейсмодислокации (по данным В.С. Хромовских); Ряд 4 - импульсы релаксации (микроземлетрясения) в районе размещения НВАЭС (по данным ИДГ РАН); Ряд 5 - землетрясения Крыма (по данным Б.Г. Пустовитенко и Т.А. Пантелеевой), Е дельные прогнозные деформации при хрупком разрушении при одноосном сжатии; $\mathrm{E}_{\mathrm{xp} \mathrm{вс}}$ - предельные прогнозные деформации при хруп-

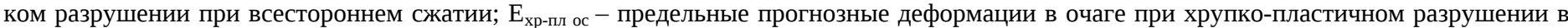
условиях одноосного сжатия; $\mathrm{E}_{\text {хр-пл вс }}$ - предельные прогнозные деформации при хрупко-пластичном разрушении при всестороннем сжатии.

Fig. 1. Dependence of decimal logarithms of forecasted critical strain (lgE) in foci in case of brittle (xp) and brittle plastic (xp-пл) destruction under all-round (вс) and uniaxial (ос) compression and observed deformations in foci from decimal logarithm of fault length, lgL (km) in earthquake foci. Row 1 - sub-foci (or rigid foci) (according to T.G. Rautian); Row 2 - smooth (weak) foci (according to T.G. Rautian); Row 3 - seismic dislocations (according to V.S. Khromovskikh); Row 4 - relaxation impulses (micro-earthquakes) near NV Nuclear Power Station (according to data from Institute of Geosphere Dynamics of Russian Academy of Sciences (IDG RAS); Row 5 - earthquakes of Crimea (according to data by

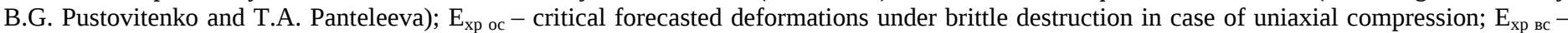
critical forecasted deformations in foci under brittle destruction in case of omniaxial compression; $\mathrm{E}_{\text {хр-пл ос }}$ - critical forecasted deformations in foci under brittle-plastic destruction in case of uniaxial compression; $\mathrm{E}_{\text {хр-пл вс }}-$ critical forecasted deformations under brittle-plastic destruction in case of omniaxial compression.

если имеет место зацеп и накопление дополнительных напряжений и деформаций не только на зацепе, но и в зоне его влияния. При землетрясении поверхностное отражение дислокации является поверхностным отражением зацепа меньшего порядка, в то время как снимаемые напряжения в зоне влияния зацепа (структур более высокого порядка) поверхностного проявления не находят.

Для оценки наиболее вероятной магнитуды принято соотношение:

$$
\mathrm{M}_{\mathrm{B}}=\lg \mathrm{L}_{\mathrm{B}}+5.5 \text {, }
$$

где $\mathrm{M}_{\mathrm{B}}$ - наиболее вероятное значение магнитуды; $\mathrm{L}_{\mathrm{B}}-$ длина разрыва в очаге, км.

Соотношения (7а и 7б) сопоставлены с аналогичными зависимостями других авторов (рис. Зб). Анализ данных рис. 3 позволяет предположить, что магнитуда 8.5 является наиболее вероятным верхним пределом сейсмического потенциала землетрясений $\mathrm{M}_{\text {пр }}$ (при точности определения порядка 0.5 единицы магнитуды).

С такими сильнейшими землетрясениями могут быть связаны первичные сейсмогенные дислокации (разрывы) XVI порядка и меньше (согласно классификации М.В. Пиотровского - А. Кайе), имеющие длину 1000 км и менее [Пиотровский, 1964; Кайе и др., 1959].

Действительно, область, ограниченная соотношением (7а) и верхним пределом магнитуд $\mathrm{M}_{\text {пр }}=8.5$, включает в себя оценки магнитуд, полученные с использованием широкоизвестных соотношений [Болт, 1984; Хромовских, 1986; Iida, 1959, 1965; Tocher, 1958; u $\partial p$.]. Практически все соотношения пересекают предельное соотношение (7б) на уровне $\mathrm{M} \leq 8.5$ при длине разрыва в очаге 1000 км и менее.

С учетом преобладающего соотношения горизонтальных и вертикальных размеров сильнейших очагов 


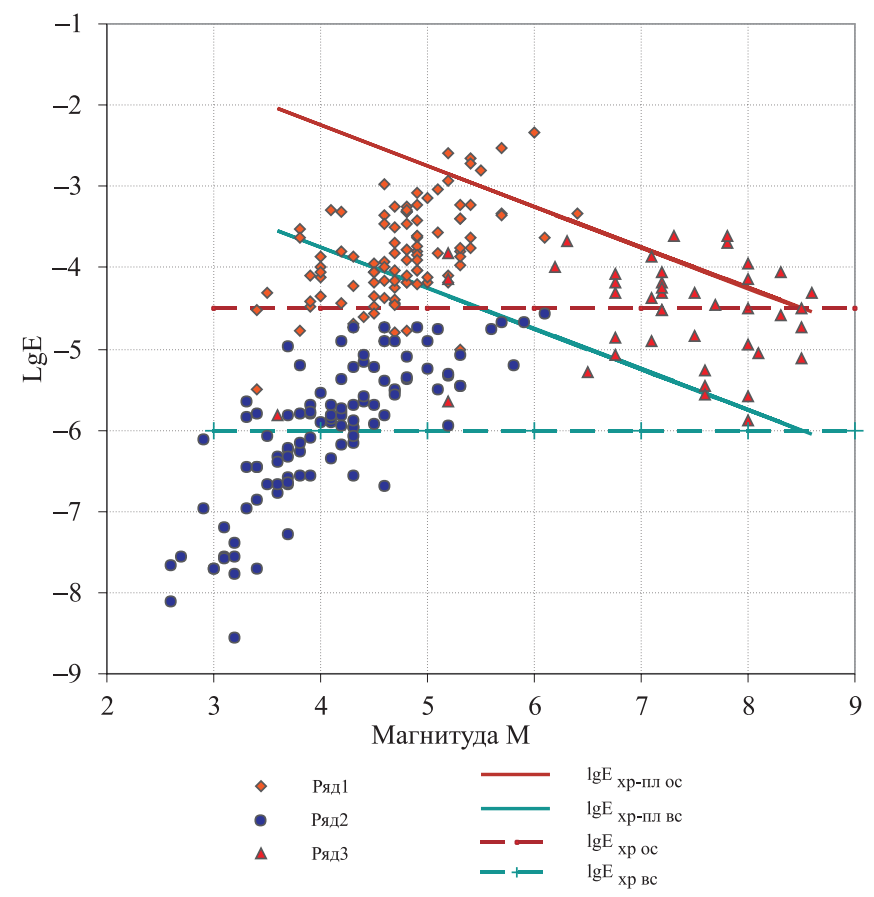

Рис. 2. Зависимость десятичных логарифмов прогнозных предельных деформаций (lgE) в очаге при хрупком (хр) и хрупко-пластичном (хр-пл) разрушении при всестороннем (вс) и одноосном (ос) сжатии и наблюденных деформаций в очагах землетрясений от магнитуды (M). Ряд 1 - субочаги (или жесткие очаги) (по данным Т.Г. Раутиан); Ряд 2 - гладкие (или вялые) очаги (по данным Т.Г. Раутиан); Ряд 3 -

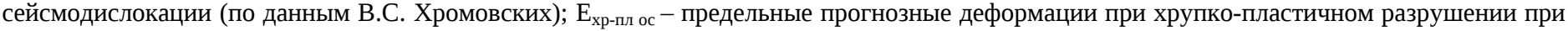

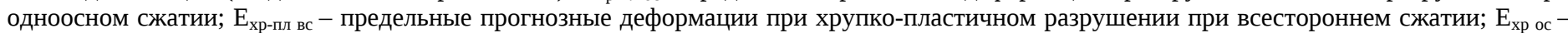
предельные прогнозные деформации при хрупком разрушении при одноосном сжатии; $\mathrm{E}_{x р}$ вс - предельные прогнозные деформации при хрупком разрушении при всестороннем сжатии.

Fig. 2. Dependence of decimal logarithms of forecasted critical strain (lgE) in foci in case of brittle (xр) and brittle plastic (xp-пл) destruction under all-round (Bс) and uniaxial (ос) compression and observed deformations in foci from earthquake magnitude, M. Row 1 - sub-foci (or rigid foci) (according to T.G. Rautian); Row 2 - smooth (weak) foci (according to T.G. Rautian); Row 3 - seismic dislocations (according to V.S. Khromovskikh); $\mathrm{E}_{\text {хр-пл ос }}$ - critical forecasted deformations in foci under brittle-plastic destruction in case of uniaxial compression; $\mathrm{E}_{\text {хр-пл вс }}-$ critical forecasted deformations under brittle-plastic destruction in case of omniaxial compression; $E_{x p ~ o c}$ - critical forecasted deformations under brittle destruction in case of uniaxial compression; $\mathrm{E}_{\text {хр вс }}$ - critical forecasted deformations in foci under brittle destruction in case of omniaxial compression.

землетрясений, близкого к 2.5, можно предположить, что очаг такого землетрясения достигает глубины порядка 400 км. Это значение корреспондируется с глубиной залегания (300-400 км) второго скачка нарастания скорости распространения сейсмических волн [Тяпкин, 1988].

Формирование более протяженных разрывов при землетрясениях могло происходить или на более ранних этапах геологического развития Земли, когда твердая оболочка Земли была менее раздроблена, или в результате многократно повторяющихся сейсмических событий.

Соотношение, аналогичное соотношению (7a), контролирует минимальный уровень рассеяния магнитуд сейсмодилокаций в зависимости от длины разрыва в очаге земной коры в условиях всестороннего сжатия:

$\mathrm{M}_{\text {мин хр-пл вс }}=1.5 \lg \mathrm{L}_{\text {мах }}+3.0$.

Соотношение (7в) соответствует верхнему пределу упругого деформирования и хрупкого разрушения при всестороннем сжатии.

Анализ рис. Зб позволяет отметить значительную неопределенность оценки магнитуды на основании регрессионных соотношений, определяющих зависимость магнитуды от длины разрыва в очаге в различных районах земного шара. Тем не менее эти соотношения не противоречат хорошо известной логарифмической зависимости магнитуды от предельной длины разрыва в очаге (или протяженности активизированного разлома) и однозначно указывают на существование предельных величин (магнитуды и длины разрыва в очаге) при сильнейших землетрясениях. В условиях одноосного сжатия наблюдается четкая сходимость предельных значений магнитуд и длин разрывов к Mпр=8.5 и Lмax=1000 км соответственно. При этом при меньших размерах очагов при фиксированной длине разрыва в очаге наблюдается больший разброс магнитуд и тем больший, чем меньше размер очага. Это не позволяет при оценке сейсмической опасности 


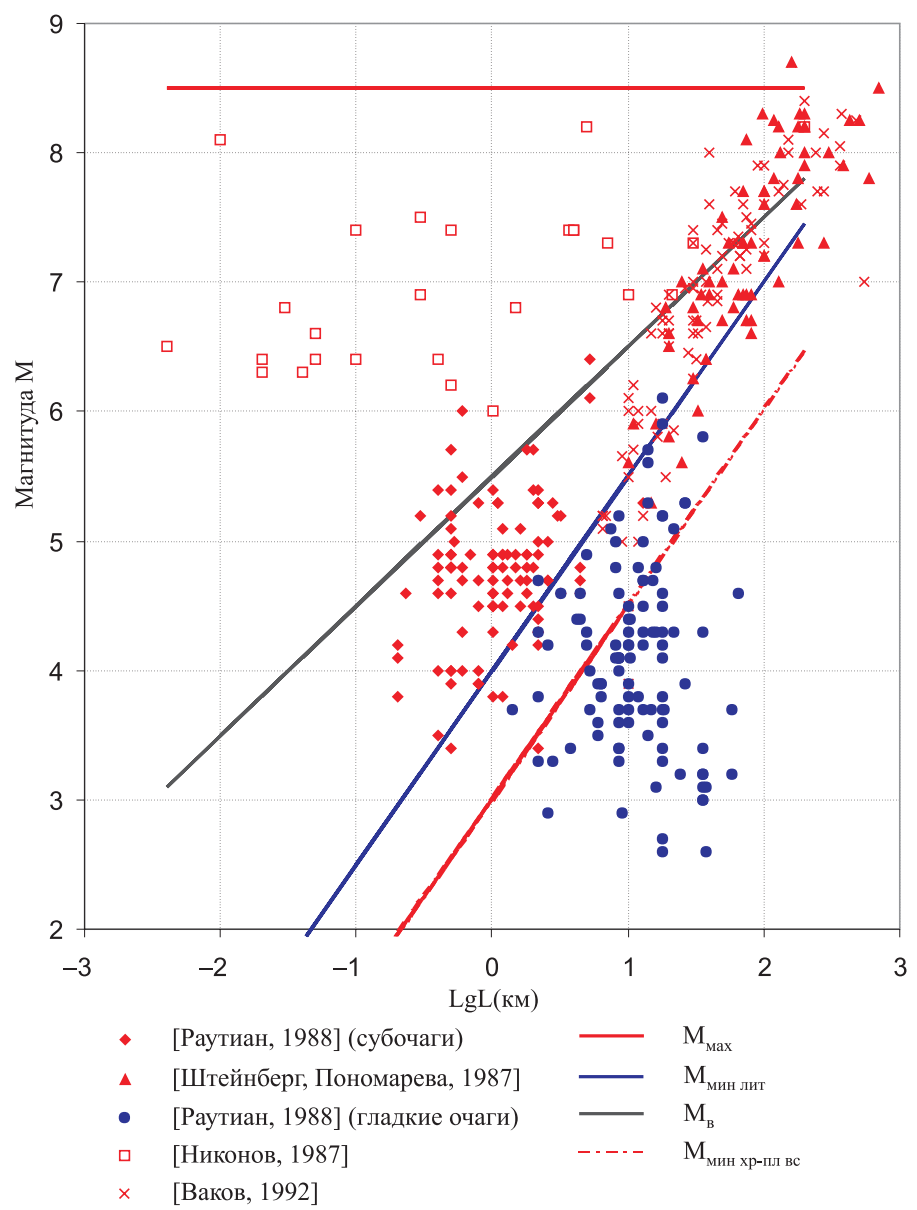

Рис. За. Зависимость магнитуды от десятичного логарифма длины разрыва $\mathrm{L}($ км) в очаге.

Fig. 3a. Dependence of earthquake magnitude from fault length $(\mathrm{L}, \mathrm{km})$ in earthquake foci.

ответственных объектов пользоваться регрессионными соотношениями, отражающими средние значения контролируемых параметров случайных выборок данных, не учитывающих условия формирования и проявления землетрясений.

\section{3. ЗАВИСИМОСТЬ АМПЛИТУДЫ ПОДВИЖКИ ОТ ДЛИНЫ РАЗРЫВА В ОЧАГЕ}

Существование при сильнейших землетрясениях предельной длины разрыва в очаге подтверждается особенностями рассеяния предельных амплитуд подвижек в зависимости от длины разрыва в очаге (рис. 4а). Зависимость предельной амплитуды подвижки от длины разрыва в очаге при одноосном сжатии и хрупко-пластическом разрушении имеет вид [Бугаев, Спuвак, 2002]:

$$
\lg \mathrm{A}_{\text {хр-пл ос }}=0.5 \lg \mathrm{L}_{0} \text {, }
$$

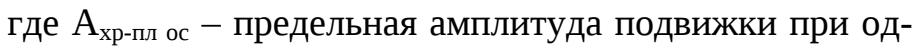

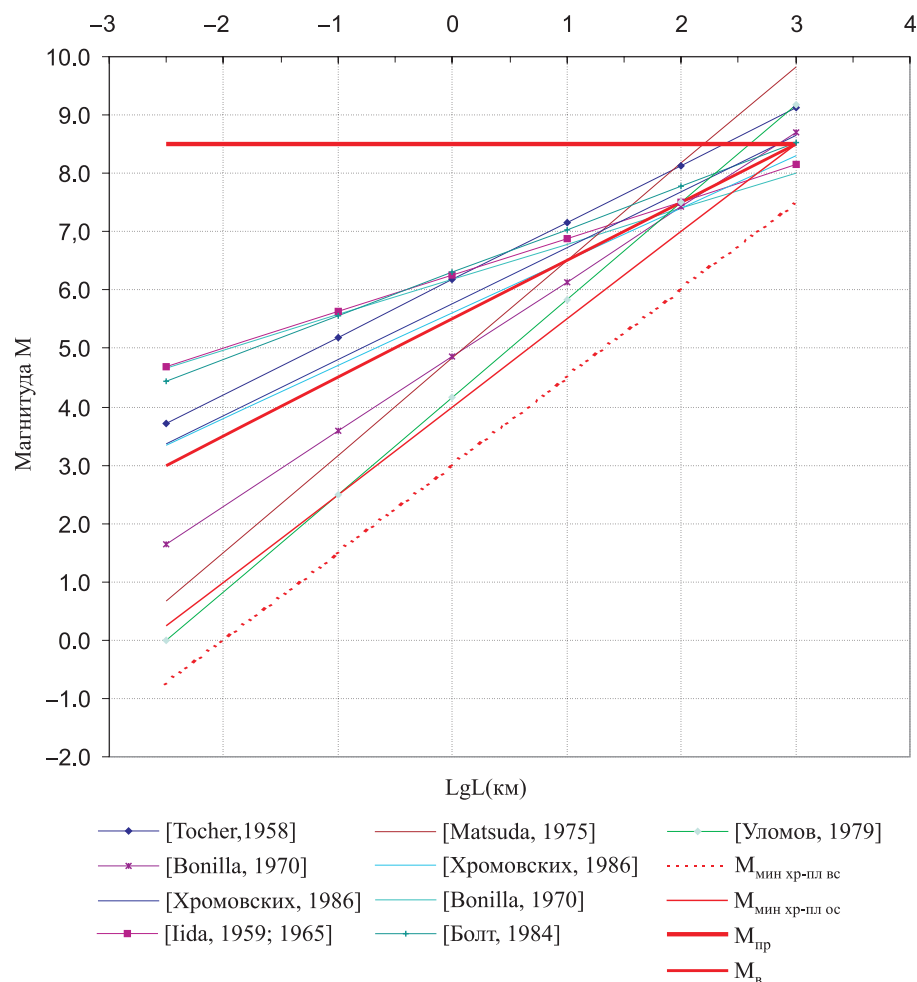

Рис. Зб. Сопоставление предельных и альтернативных оценок магнитуд от десятичных логарифмов длины разрыва L (км) в очаге (по данным разных авторов).

Fig. 36. Comparison of critical and alternative evaluations of magnitudes from decimal logarithms of fault length, $\mathrm{L}(\mathrm{km})$ in foci (according to data from different authors).

ноосном сжатии и хрупко-пластическом разрушении, м; $\mathrm{L}_{0}$ - длина разрыва в очаге, км.

Нижний предел амплитуды подвижки хрупко-пластических деформаций в очаге при всестороннем сжатии описывается соотношением:

$$
\lg \mathrm{A}_{\text {хр-пл вс }}=0.5 \lg \mathrm{L}_{0}-1.5
$$

где $\mathrm{A}_{\text {хр-пл вс }}$ - предельная амплитуда подвижки при всестороннем сжатии и хрупко-пластическом разрушении, м; $\mathrm{L}_{o}$ - длина разрыва в очаге, км.

Нижний предел рассеяния амплитуд подвижек при сейсмогенных подвижках в очагах землетрясений контролируется пределом упругого деформирования и хрупкого разрушения при всестороннем сжатии и описывается соотношением:

$$
\lg \mathrm{A}_{\text {хр вс }}=\lg \mathrm{L}_{0}-3.0
$$

где $\mathrm{A}_{\mathrm{xp} \mathrm{вс}}$ - предельные амплитуды подвижки в очаге при хрупком разрушении среды в условиях всестороннего сжатия, $\mathrm{m} ; \mathrm{L}_{\mathrm{o}}$ - длина разрыва, км.

Этот уровень контролируется деформациями, соот- 
ветствующими пределу упругого деформирования и хрупкого разрушения среды в очаге порядка $\mathrm{E}_{\mathrm{xp} \mathrm{вс}}=$ $=10^{-6}$. В действительности соотношение (8в) может иметь вид:

$$
\lg \mathrm{A}_{\text {хр вс }}=\lg \mathrm{L}_{\mathrm{o}}-2.75
$$

и соответствовать величине деформации $\mathrm{E}_{\mathrm{xр} \mathrm{вс1}} \approx 1.8 \cdot 10^{-6}$ или $\lg \mathrm{E}_{\mathrm{xр} \mathrm{вс1}}=-5.75$, отражающей условия упругого деформирования и хрупкого разрушения при всестороннем сжатии.

Этот предел контролирует очень ограниченное число сейсмических событий - единичные землетрясения, что указывает на преобладание хрупко-пластического разрушения пород в очагах сильных землетрясений.

С учетом данных о параметрах гладких очагов, приведенных в работе [Раутиан, 1988], установлен верхний предел амплитуды подвижки для условий упругого деформирования и хрупкого разрушения в условиях одноосного сжатия:

$$
\lg \mathrm{A}_{\text {хр-пл ос }}=\lg \mathrm{L}_{\mathrm{o}}-1.5 \text {, }
$$

здесь $\mathrm{A}_{\text {хр-пл ос }}$ верхний предел амплитуды подвижки для условий упругого деформирования и хрупкого разрушения в условиях одноосного сжатия, м.

Величина максимальной длины разрыва в условиях одноосного сжатия может быть оценена с учетом соотношений (8а) и (8д) и составит 1000 км.

Предельный размер очага землетрясения ограничивает верхний предел магнитуды в условиях одноосного сжатия при упругом деформировании и хрупком разрушении среды и контролируется пределом упру-

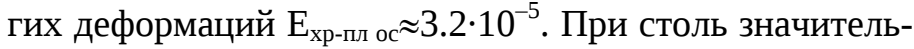
ных деформациях и размерах области подготовки очага в процесс деформирования, возможно, вовлекается и верхняя мантия. В пределах глубокозалегающих частей области подготовки потенциальных очагов большей протяженности, захватывающих верхнюю мантию, по-видимому, преобладает вязкое течение среды, которое способствует проявлению волны разгрузки при сильных землетрясениях.

Данные о рассеянии амплитуды подвижки в зависимости от длины разрыва подтвердили существование предельных значений магнитуды, длины разрыва и амплитуды, которые соответственно равны 1000 км, 8.5 и 232 м.

Минимальный уровень предельных амплитуд подвижек в очаге в условиях хрупко-пластического деформирования среды при всестороннем сжатии определяется соотношением (8б) и совместно с соотношением (8г), установленным для величины упругой пре-

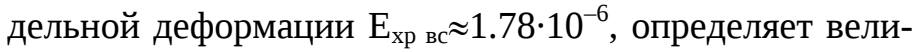
чину предельной длины разрыва в условиях всестороннего сжатия, равную 316 км.

Значительная раздробленность земной коры не позволяет в условиях всестороннего сжатия и при столь низких деформациях формироваться более протяженным разрывам. При этом максимальная величина эффективной магнитуды $\mathrm{M}_{\text {мах }}=8.0$.

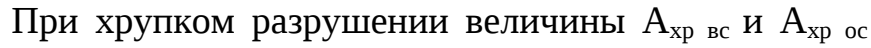
изменяются прямо пропорционально изменению $\mathrm{L}_{\mathrm{p}}$, a при хрупко-пластическом разрушении среды величи-

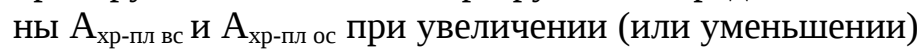
длины разрыва в $k$ раз соответственно изменяются лишь в $\sqrt{k}$ раз.

\section{4. ЗАВИСИМОСТЬ АМПЛИТУДЫ ПОДВИЖКИ ОТ МАГНИТУДЫ}

Соотношения, контролирующие область рассеяния амплитуды подвижки в очаге в зависимости от магнитуды, были установлены на основании соотношений $(8 a, 8 б, 8 г, 8 д)$ и зависимости магнитуды $\mathrm{M}_{\text {мин хр-пл ос от }}$ длины разрыва $\mathrm{L}_{\mathrm{p}}$ и имеют вид:

$$
\begin{aligned}
& \lg \mathrm{A}_{\text {хр-пл ос }}=0.333 \mathrm{M}-1.333, \\
& \lg \mathrm{A}_{\text {хр-пл вс }}=0.333 \mathrm{M}-2.83, \\
& \lg \mathrm{A}_{\text {хр ос }}=0.667 \mathrm{M}-4.16, \\
& \lg \mathrm{A}_{\text {хр вс }}=0.667 \mathrm{M}-5.42 .
\end{aligned}
$$

На рис. 4а приведено распределение наблюденных амплитуд подвижек в очаге в зависимости от магнитуды землетрясения.

Соотношение (8.1) контролирует верхний предел наблюденного рассеяния амплитуд подвижек в условиях одноосного сжатия и хрупко-пластического разрушения среды в зависимости от магнитуды.

Минимальные амплитуды хрупко-пластических деформаций в условиях всестороннего сжатия определяются соотношением (8.2). Предельные амплитуды подвижки в условиях одноосного сжатия и хрупкого разрушения при пределе упругого деформирования и хрупкого разрушения $\lg \mathrm{E}_{\mathrm{xp} \mathrm{oc}}=-4.5$ определяются соотношением (8.3) и четко контролируются областью перехода от «гладких очагов» к «субочагам».

Предельные амплитуды подвижки в условиях всестороннего сжатия и хрупкого разрушения при упругих предельных деформациях $\lg \mathrm{E}_{\mathrm{xp} \mathrm{вс}}=-5.75$ определяются соотношением (8.4) и контролируют минимальные значения амплитуд подвижек при сейсмогенных дислокациях.

Следует отметить, что соотношения, контролирующие область рассеяния амплитуды подвижки в очаге в зависимости от магнитуды, также были установлены на основании соотношений (8а, 8б, 8г, 8д) и зависимости магнитуды $\mathrm{M}_{\mathrm{B}}$ от длины разрыва и имеют вид:

$$
\lg \mathrm{A}_{\text {хр-пл ос }}=0.5 \mathrm{M}_{\mathrm{B}}-2.75 \text {, }
$$




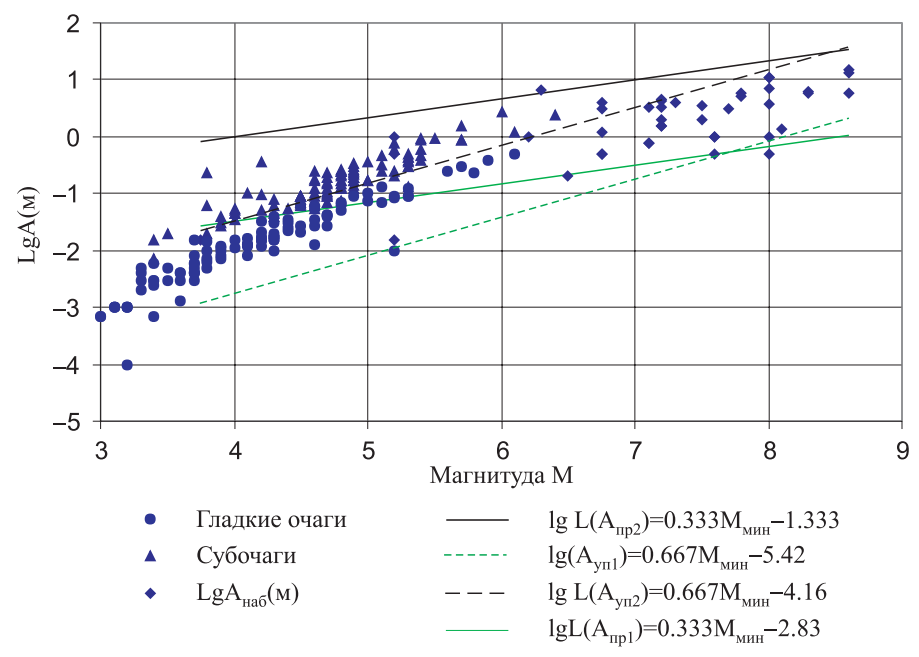

Рис. 4а. Оценка предельной величины десятичного логарифма амплитуды подвижки в очаге в зависимости от магнитуды.

Fig. 4a. Estimations of limiting displacement amplitudes in foci from earthquake magnitudes.

$\lg \mathrm{A}_{\text {хр-пл вс }}=0.5 \mathrm{M}_{\mathrm{B}}-4.25$,

$\lg \mathrm{A}_{\mathrm{xp} \mathrm{oc}}=\mathrm{M}_{\mathrm{B}}-7.0$,

$\lg \mathrm{A}_{\text {хр вс }}=\mathrm{M}_{\mathrm{B}}-8.25$.

Как предыдущие, так и эти соотношения вполне удовлетворительно обобщают экспериментальные данные и подтверждают полученные выше оценки предельной магнитуды $\mathrm{M}_{\text {хр-пл вс }}=7.75$ (8.0) и $\mathrm{M}_{\text {хр-пл ос }}=8.5$ для условий всестороннего и одноосного сжатия соответственно.

Следует, однако, отметить, что установленные с

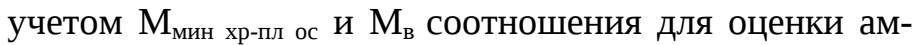
плитуды в зависимости от магнитуды имеют определенные отличия и требуется независимое прямое определение этих предельных соотношений.

Оценки предельной амплитуды подвижки при хрупком или хрупко-пластическом разрушении для условий всестороннего и одноосного сжатия, полученные на основании анализа сейсмогенных дислокаций, являются принципиально новым результатом. Эти данные позволяют устранить противоречия в оценке энергетического уровня землетрясений, устанавливаемого на основании сейсмологических и сейсмотектонических данных с учетом физических особенностей наблюдаемых явлений, структурной приуроченности очагов землетрясений и особенности упругого деформирования и хрупкого и/или хрупко-пластического разрушения среды в очаге землетрясения.

На рисунке $4 б$ предельные амплитуды подвижек в

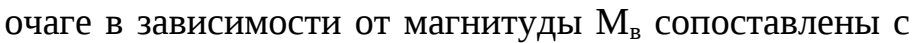
результатами других исследователей [Chinnery, 1961;

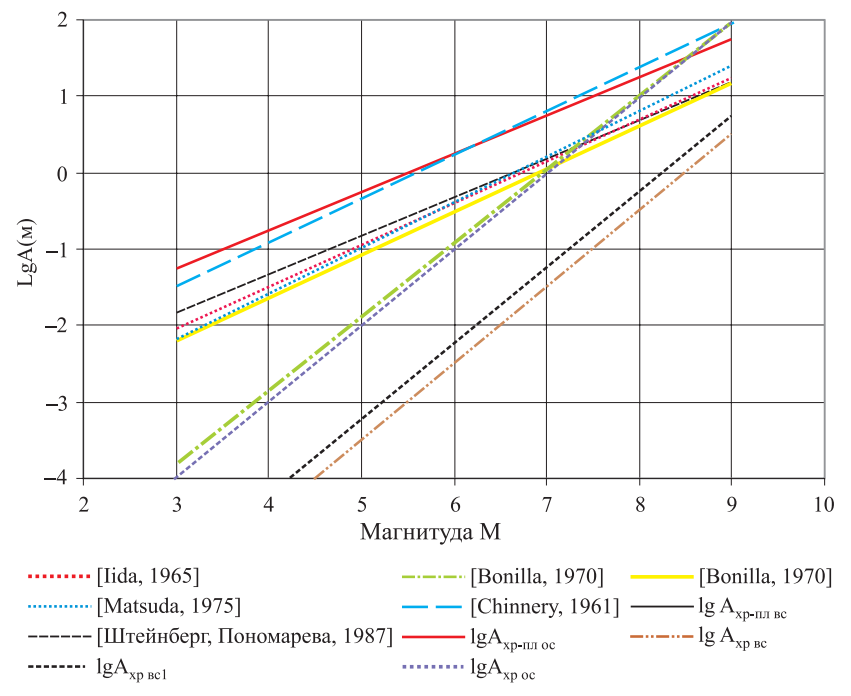

Рис. 4б. Сопоставление предельных и альтернативных оценок десятичных логарифмов амплитуды подвижки в очаге в зависимости от магнитуды.

Fig. 4б. Comparison of critical and alternative evaluations of decimal logarithms of displacement amplitudes in foci versus magnitudes.

Iida, 1959; Matsuda, 1975; и дp.]. Следует обратить внимание на тот факт, что предельные амплитуды подвижки $\left(\mathrm{A}_{\mathrm{xp-пл} \mathrm{ос}}\right)$ в очаге землетрясения близки к оценкам, представленным в работе [Iida, 1965], в то время как предельные амплитуды подвижки $\left(\mathrm{A}_{\mathrm{xp} \mathrm{ос}}\right)$ при хрупком разрушении практически совпадают с данными работы [Bonilla et al., 1984].

При этом оценки амплитуды подвижки в очаге, полученные на основании соотношений другими исследователями, располагаются в пределах области хрупко-пластического разрушения при всестороннем и одноосном сжатии.

Для территории Японии при оценке сейсмической опасности атомных станций широко используются соотношения $\lg \mathrm{L}=0.6 \mathrm{M}-2.9, \lg \mathrm{A}=0.6 \mathrm{M}-4.0$ и $\lg \mathrm{A}=\lg \mathrm{L}-$ -1.0 [Matsuda, 1975], экспериментально полученные для условий упругого деформирования и хрупкого разрушения для предела деформации в очаге землетрясения, равного $\mathrm{E}_{\mathrm{yп}}=10^{-4}$. Представленные выше результаты позволяют утверждать, что принятые для Японии соотношения справедливы для разрывов, длина которых не превышает 100 км. При этом в зависимости от длины разрыва величина М может быть 7.0 и менее. Однако в этом регионе известны и более сильные землетрясения, приуроченные к более крупным тектоническим структурам, на которые принятые для Японии соотношения не могут быть распространены, так как приводят к физически не обоснованным результатам. Например, согласно этим соотношениям при $\mathrm{L}=1000$ км магнитуда может достигать 10 , что противоречит прочностным и деформационным харак- 
теристикам среды в области подготовки и очаге землетрясения.

Соотношения [Matsuda, 1975] не учитывают возможность наличия зацепов и превышения принятого предела упругого деформирования и хрупко-пластического разрушения и проявления в результате этого более сильных сейсмических событий (бо́льших магнитуд и амплитуд подвижки в очаге), что и имело место при землетрясении 11 марта 2011 г. у восточного побережья о. Хонсю.

Таким образом, если область подготовки очага землетрясения является составной частью структуры более высокого порядка, нельзя исключить из рассмотрения возможность возникновения и более сильных сейсмических событий, чем наблюденные.

В связи с этим при оценке сейсмической опасности особое внимание следует уделять определению максимального порядка и степени тектонической активности структуры, отвечающей за подготовку очага потенциального землетрясения.

\section{5. ПРОТЯЖЕННОСТЬ ЗОНЫ ВОЗ И ПРЕДЕЛЬНАЯ ДЛИНА РАЗРЫВА В ОЧАГЕ}

Анализ рассеяния параметров сейсмогенных дислокаций позволил установить соотношение предельной длины разрыва в очаге при одноосном сжатии и при всестороннем сжатии. Это отношение равно $\sim \sqrt{10}$, сопоставимо с коэффициентом подобия $\mathrm{K}_{п}=3.3 \pm 0.95$, принятым М.А. Садовским для «кусковатой» модели геофизической среды [Садовский, 1979], и не противоречит чередующимся коэффициентам иерархичности 3 и 3.3 в эмпирическом ряде М.В. Пиотровского A. Кайе [Benedik et al., 1995; Кайе, Трикар, 1959; Пиотровский, 1964]. Землетрясения так же иерархически подобны, распределены в пространстве и подчиняются закону фрактальности - свойству подобия множеств [Mandelbrot, 1982; и др.].

Анализ данных об отношении протяженности зоны активного разлома к предельной длине разрыва в очаге, приуроченного к этой зоне [Штейнберг, Пономарева, 1987; и др.], показал, что это отношение изменяется в пределах от 3 до 10. Минимальное значение этого отношения практически совпадает с коэффициентом иерархичности, равным 3. Таким образом, протяженность области подготовки землетрясения в $\sqrt{10}$ раз превышает максимальный размер будущего очага или в 10 раз минимальный размер, при котором очаг землетрясения выходит на поверхность Земли. Обоснованность полученного диапазона подтверждается результатами других исследователей. Согласно работе [Уломов, 1995], наиболее вероятная величина этого отношения равна 3.63, а максимальная может достигать 10 и более [Комплексные геолого-геофизические исследования..., 1990; Штейнберг, Пономарева, 1987].

Анализ соотношения протяженности зон ВОЗ и предельных размеров очагов землетрясений в них позволил принять единый коэффициент иерархичности $\mathrm{k}$, который равен $\approx \sqrt{10}$ и контролирует соотношение протяженности зон ВОЗ и предельных параметров очагов землетрясений в них при деформировании среды в условиях всестороннего и одноосного сжатия и хрупкого или хрупко-пластического разрушения. Этот результат не противоречит условию самоподобия [Гейликман, Писаренко, 1989; Mandelbrot, 1982] и отражает степенную зависимость параметров очага землетрясения от его размера.

\section{5. КРИТЕРИИ ВЫЯВЛЕНИЯ ЖЕСТКИХ И ВЯЛЫХ ОЧАГОВ ЗЕМЛЕТРЯСЕНИЙ}

Рассмотренные выше деформационные характеристики очагов землетрясений позволили установить критерии разделения тектонических сейсмических событий на жесткие и вялые землетрясения с учетом:

1) особенностей проявления очагов землетрясений в пределах платформенной территории и активных областей;

2) закономерностей взаимного изменения параметров очагов в зависимости от условий подготовки очага и характера его реализации.

С учетом данных, представленных на рисунках 1 и 2, установлено два предела хрупкого разрушения, которые не зависят от размера очага и магнитуды (соотношения (1) и (2)): $-\mathrm{E}_{\mathrm{xp} \mathrm{ос}}=\sim 3 \cdot 10^{-5}-$ для условий одноосного сжатия, $-\mathrm{E}_{\mathrm{xp} \mathrm{вс}}=210^{-6}-$ для условий всестороннего сжатия, и предел хрупко-пластического разрушения (соотношение (3)), имеющий вид: $\lg \mathrm{E}_{\text {хр-пл ос }}=$ $=-0.5 \lg \mathrm{L}_{0}-3.0$ и отражающий зависимость предела хрупко-пластической деформации от размера разрыва в очаге (или размера очага), где $\mathrm{L}_{0}$ - размер очага, км;

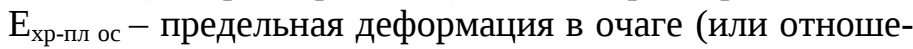
ние максимальной амплитуды подвижки в очаге к его длине).

При этом предварительно установлено, что предельные деформации в очагах импульсов релаксации, как правило, не превышают $\sim 3 \cdot 10^{-7}$. Возможно, это связано с особенностями проявления очагов землетрясений в условиях слабоактивной территории и постоянной сменой локальных напряжений, что требует дополнительных исследований.

Двум пределам упругого деформирования и хрупкого разрушения соответствуют максимальные магнитуды, определяемые в зависимости от минимальной длины разрыва в очаге $\mathrm{L}_{\mathrm{o}}(\mathrm{KM})$ соотношениями: для $\mathrm{E}_{\mathrm{xp} \mathrm{ос}}=\sim 3 \cdot 10^{-5}$ соотношением (7a); для $\mathrm{E}_{\mathrm{xp} \mathrm{вс}}=\sim 10^{-6}$ соотношением (7в).

С учетом соответствия размера очага и максимального размера эллипса неопределенности из соотношений (7а) и (7в) рассчитывались максимальные магнитуды $\mathrm{M}_{\text {вс }}$ и $\mathrm{M}_{\text {ос }}$, которые сопоставлялись с наблюденной $\left(\mathrm{M}_{\text {наб}}\right)$ : 


$$
\begin{aligned}
& \mathrm{dM}_{\mathrm{oc}}=\mathrm{M}_{\text {наб }}-\mathrm{M}_{\text {мин хр-пл ос }}, \\
& \mathrm{dM}_{\mathrm{BC}}=\mathrm{M}_{\text {наб }}-\mathrm{M}_{\text {мин хр-пл вс }} .
\end{aligned}
$$

При $\mathrm{dM} \geq 0$ имеем жесткие очаги, которые, как правило, формируются в условиях зацепа, и их спектр может иметь как минимум две угловые частоты [Раутиан, 1988]. Одна из них контролируется размером «зацепа» и скоростью его вспарывания, а вторая отражает эффект снятия нагрузки в пределах зоны влияния «зацепа» и контролируется накопленной амплитудой упругого смещения за время подготовки очага и скоростью смещения массовых частиц.

При $\mathrm{dM}<0$ имеем вялые очаги, их механизм, возможно, связан с образованием трещин отрыва и трещин сдвига. Если трещины отрыва могут характеризоваться интенсивными высокочастотными импульсами, то механизм образования трещин сдвига, повидимому, подобен механизму импульсов релаксации [Кочарян, Спивак, 2003], при которых очаг является результатом проскальзывания смежных блоков по ослабленной межблоковой границе и характеризуется минимальной амплитудой А(м) и максимальным размером подвижки $\left(\mathrm{L}_{\mathrm{o}}, \mathrm{KM}\right)$.

Детальное рассмотрение динамических характеристик различных типов очагов представляет самостоятельную задачу, важную для понимания сейсмического процесса и прогноза динамических параметров сейсмических воздействий, и требует самостоятельного детального изучения при проведении детальных сейсмологических исследований.

Соотношения (9) и (10) определяют два физически обоснованных критерия разделения сейсмических событий на жесткие и вялые очаги для различных условий деформирования и хрупкого разрушения земной коры. Соотношение (10) рекомендуется использовать в пределах слабоактивных территорий, где имеет место относительно низкий уровень тектонических напряжений и сейсмической активности и относительно низкие тектонические деформации. Соотношение (9) предпочтительно применять в сейсмически активных областях, где наблюдается большое количество землетрясений разных типов (жестких и вялых, структурированных и рассеянных) и есть явные предпосылки для существования зацепов, которые играют определяющую роль в подготовке очагов сильных землетрясений. Следует отметить, что первые сведения о существовании зацепов и их роли в механике подготовки тектонического землетрясения автор получил из монографии И.П. Добровольского [Добровольский, 1984].

\section{6. РЕЗУЛЬТАТЫ АНАЛИЗА УТОЧНЕННОГО И ТРАДИЦИОННЫХ КАТАЛОГОВ}

Анализ данных уточненного каталога зоны СанАндреас в Калифорнии за период с января 1984 г. по май 2003 г. [http://www.ncedc.org] выполнен с учетом принятого критерия разделения событий на жесткие и вялые землетрясения для условий одноосного сжатия. Для данного района выполнен анализ традиционных каталогов исторических землетрясений (за период порядка 220 лет) и инструментальных данных о землетрясениях с $\mathrm{M} \geq 5.0$ за 9 лет после мая 2003 г. Представлены результаты анализа каталога землетрясений для района размещения АС Фукусима-1, а также каталога форшоков и афтершоков (за первые дни) землетрясения 11 марта 2011 г. у восточного побережья острова Хонсю. Результаты оценки графиков повторяемости для зоны разлома Сан-Андреас сопоставлены с результатами работы [Kocharyan et al., 2010], что подтвердило актуальность разделения сейсмических событий на жесткие и вялые очаги и раздельной оценки параметров сейсмического режима при рассмотрении физической природы нелинейности региональных графиков повторяемости.

\section{1. О ФИЗИЧЕСКОЙ ПРИРОДЕ НЕЛИНЕЙНОСТИ ГРАФИКОВ ПОВТОРЯЕМОСТИ}

Разделение сейсмических событий, включенных в уточненный каталог, на жесткие и вялые очаги выполнено на основании соотношения (9) с учетом наблюденной магнитуды и размера очага, принятого согласно максимальному горизонтальному размеру эллипса неопределенности. Это позволило существенно расширить возможности изучения сейсмического процесса в пространстве и времени и рассмотреть физическую природу нелинейности графиков повторяемости.

Для района в целом (площадь порядка 250 тыс. км²) с учетом принятого критерия были получены выборки данных жестких и вялых очагов, на основании которых были рассчитаны графики повторяемости жестких очагов ( $\mathrm{T}=19$ лет, жесткие) и графики повторяемости вялых очагов ( $\mathrm{T}=3.5$ года, вялые). Для удобства сравнения графики повторяемости представлены в виде зависимостей десятичных логарифмов суммарного количества событий с $\mathrm{M} \geq \mathrm{M}_{\mathrm{i}}$, приведенного к одному году и единичной площади 1000 км², от магнитуды. Для рассматриваемого района графики повторяемости жестких и вялых очагов сопоставлены с графиками повторяемости исторических (исторические события, $\mathrm{T}=220$ лет) и инструментальных (T=9 лет) данных (рис. 5). График повторяемости исторических землетрясений для представительного диапазона магнитуд $(\mathrm{M} \geq 6.0)$ имеет вид:

$$
\lg \mathrm{N}=2.93-0.92 \mathrm{M}_{\text {ист }}
$$

и, продленный в область малых магнитуд, показывает положение графиков ( $\mathrm{T}=19$ лет, жесткие) и ( $\mathrm{T}=9$ лет). При этом график повторяемости вялых очагов для района в целом ( $\mathrm{T}=3.5$ года, вялые) в диапазоне представительных магнитуд от 1.5 до 5.0 имеет существен- 


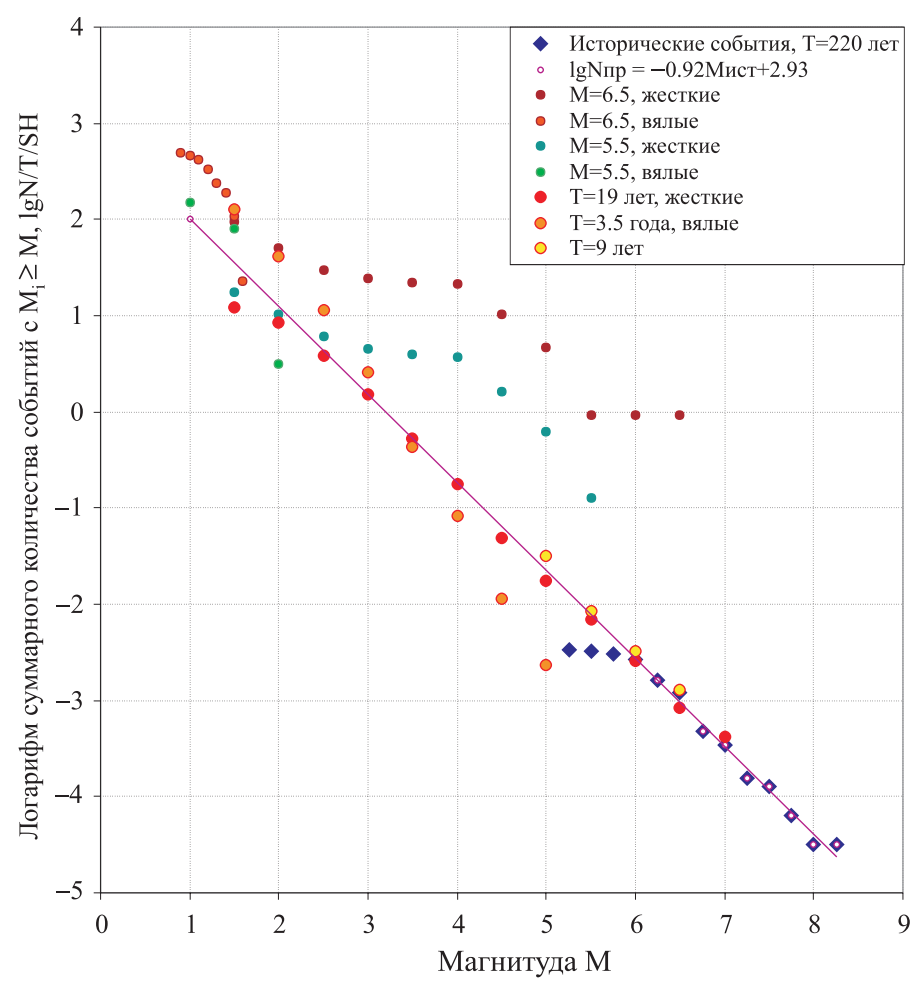

Рис. 5. Логарифмы суммарного количества событий с $\mathrm{M}_{\mathrm{i}} \geq \mathrm{M}$, приведенного к 1 году и площади $1000 \mathrm{~km}^{2}$, для рассматриваемого района: на основании исторических событий (исторические события), жестких (жесткие, $\mathrm{T}=19$ лет) и вялых очагов (вялые, $\mathrm{T}=3.5$ года) по данным уточненного каталога и событий с $\mathrm{M} \geq 5.0$ за последующие 9 лет (Т=9 лет); для двух локальных участков - эпицентральных зон землетрясений $(\mathrm{M}=5.5)$ и $(\mathrm{M}=6.5)$ для жестких и вялых очагов соответственно. График повторяемости исторических землетрясений для представительного диапазона магнитуд $(\mathrm{M} \geq 6.0)$ имеет вид: $\lg \mathrm{N}=2.93-0.92 \mathrm{M}_{\text {ист }}$ и контролирует особенности проявления жестких и сильных землетрясений для района в целом, в то время как для локальных участков графики повторяемости жестких и вялых очагов могут существенно отклоняться от него.

Fig. 5. Logarithm of the total number of seismic events with $M_{i} \geq M$, reduced to one year and an area of $1000 \mathrm{~km}^{2}$, for the area under study. The logarithms are based on the updated catalogue data on historical events, stiff (stiff, $\mathrm{T}=19$ years) and non-stiff foci (non-stiff, $\mathrm{T}=3.5$ year) and data on events with c $M \geq 5.0$ for the next 9 years ( $T=9$ years). Based on data from two local sites, the logarithms are given for epicentre zones of earthquakes of $\mathrm{M}=5.5$ and $\mathrm{M}=6.5$ for stiff and non-stiff foci, correspondingly. For the representative set of magnitudes $(M \geq 6.0)$, a historical earthquake recurrence curve is as follows: $\operatorname{lgN}=$ $=2.93-0.92 \mathrm{M}_{\text {ист }}$; it controls specific features of manifestation of stiff and strong earthquakes in the region in general, while recurrence curves of stiff and non-stiff foci for local sites may considerably deviate from this curve.

но больший наклон $\mathrm{b}=-1.39$ и активность $\mathrm{a}_{\mathrm{M}=0}=4.4$.

Именно наличие вялых очагов определяет основное отличие графика повторяемости исторических землетрясений от графика повторяемости, полученного для рассматриваемого района в работе [Kocharyan et al., 2010] и имеющего вид:

$$
\lg \mathrm{N}=2.32-0.937 \mathrm{M}
$$

где $\mathrm{M}$ - магнитуда, $\mathrm{N}$ - суммарное количество собы-

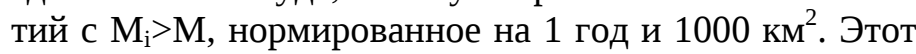
график получен для района в целом с учетом всего уточненного каталога, он линеен в широком диапазоне магнитуд от 1 до 7.

В отличие от графика повторяемости исторических землетрясений соотношение (12) показывает больший угол наклона, что обусловлено вкладом в суммарное количество событий вялых очагов, и меньшую сейсмическую активность. Это определяет недооценку максимального потенциала редких сейсмических событий с учетом соотношения (12) по сравнению с оценками по историческим данным и жестким очагам:

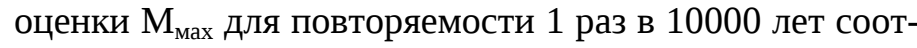
ветственно равны 6.7 и 7.5. Выполненный сопоставительный анализ отражает актуальность раздельного учета жестких и вялых очагов (при отсутствии соответствующей информации не менее актуален и раздельный учет слабых с $\mathrm{M}<5.0-6.0$ и сильных с $\mathrm{M} \geq 6.0$ событий) при оценке долговременной сейсмической опасности.

Для сравнения на рис. 5 представлены графики повторяемости для локальных участков проявления относительно сильных землетрясений ( $\mathrm{M}_{\text {мах наб }}=5.5$ и $\mathrm{M}_{\text {мах }}$ наб=6.5) в пределах юго-восточной части зоны влияния разлома Сан-Андреас. Особенностью данного участка является то, что он попадает в зону более интенсивного взаимодействия Тихоокеанской и Североамериканской платформ. Сравнение локальных графиков повторяемости жестких и вялых очагов с долговременным графиком повторяемости для района в целом по историческим данным показало, что для жестких очагов абсолютное значение наклона графиков повторяемости заметно уменьшается, а для вялых, как правило, возрастает (рис. 5). Имеет место явное изменение соотношения количества вялых и жестких очагов в пользу жестких для относительно сильных событий и, наоборот, в пользу вялых для относительно слабых событий. Такое изменение соотношения числа слабых и сильных событий может быть одной из причин нелинейности региональных графиков повторяемости, учитываемой при ОСР-97 и определяющей повышение сейсмической опасности.

Весьма важным для понимания сейсмического процесса представляется рассмотрение графика повторяемости для локальной зоны проявления землетрясения 23.11.1984 г. ( $\mathrm{M=5.5}$ и $\mathrm{H=12}$ км), расположенной в северо-восточной части (37.38-37.48 ${ }^{\circ}$ с.ш. и $-118.53-$ $118.68^{\circ}$ в.д.) зоны влияния разлома Сан-Андреас. Особенностью данного участка является то, что он расположен за зоной разлома Сан-Андреас в пределах территории с менее интенсивными деформациями и напряжениями. По данным ряда наблюдений за 17.5 года в пределах локального участка установлено, что сейсмические события в диапазоне магнитуд от 2 до 5.5 относятся к жестким очагам и для них получен график повторяемости с весьма пологим углом наклона 


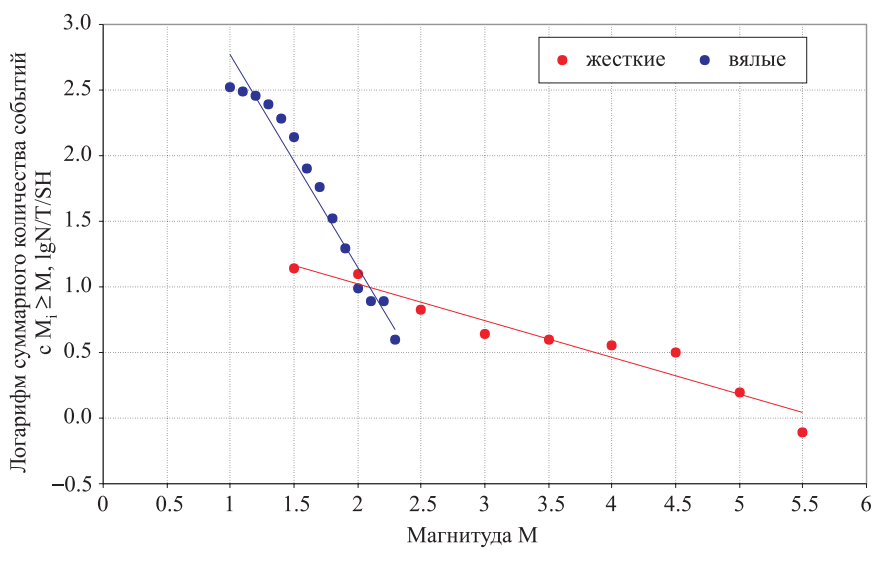

Рис. 6. Логарифм суммарного количества событий с $\mathrm{M}_{\mathrm{i}} \geq \mathrm{M}$, $\operatorname{lgN}$,

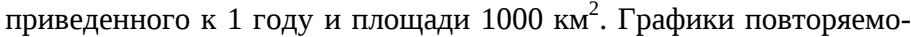
сти для эпицентральной зоны землетрясения 23.11.1984 г. (M=5.5 и $\mathrm{H}=12$ км) имеют вид: $\lg N_{\text {ж}}=1.59-0.28 \mathrm{M}_{\text {ж }}$ (жесткие очаги), $\lg \mathrm{N}_{\mathrm{B}}=$ =4.38-1.61M $\mathrm{M}_{\mathrm{B}}$ (вялые очаги).

Fig. 6. Logarithm of the total number of seismic events with $M_{i} \geq M$, $\operatorname{lgN}$, reduced to one year and an area of $1000 \mathrm{~km}^{2}$. Recurrence curves for the epicentre zone of 23 November 1984 earthquake $(M=5.5$ and $\mathrm{H}=12 \mathrm{~km}$ ) are as follows: $\lg \mathrm{N}_{\mathrm{K}}=1.59-0.28 \mathrm{M}_{\text {ж}}$ (stiff foci), $\operatorname{lgN_{\mathrm {B}}=}$ $=4.38-1.61 \mathrm{M}_{\mathrm{B}}$ (non-stiff foci).

(рис. 6). В пределах этого же участка за 3.5 года наблюдений высокочувствительной сетью зарегистрировано большое количество землетрясений в диапазоне магнитуд от 1 до 2, которые имеют вялые очаги, для которых установлен весьма крутой угол наклона графика повторяемости (рис. 6). Учет всех сейсмических событий без разделения на вялые и жесткие очаги наглядно отражает нелинейность графика повторяемости и определяет увеличение абсолютного значения наклона графика повторяемости, что, хотя и менее выраженно, было отмечено при сравнении соотношений (11) и (12), полученных для района в целом. Такое изменение соотношения вялых и жестких очагов в сторону вялых, по-видимому, обусловлено относительно более низким уровнем тектонических напряжений и локальным характером их проявления. В то же время график повторяемости жестких очагов определяется единым каркасом взаимодействующих между собой структур различного порядка, отвечающих за подготовку сильного сейсмического события в зоне разлома Сан-Андреас. В первом приближении этот график может быть использован для оценки времени ожидания сильного сейсмического события определенной магнитуды в зоне влияния зацепа, контролирующего целостность каркаса из жестких блоков.

Для более детального анализа влияния жесткости очагов землетрясений на параметры графика повторяемости для зоны влияния разлома Сан-Андреас (для района в целом) рассчитаны графики повторяемости вялых и жестких очагов и супержестких очагов (рис. 7). Жесткие очаги подразделены на жесткие $\left(\mathrm{M}_{\text {ос }}<\mathrm{M}_{\text {наб }}<\mathrm{M}_{\mathrm{B}}\right)$ и супержесткие $\left(\mathrm{M}_{\text {наб }}>\mathrm{M}_{\mathrm{B}}\right)$, где $\mathrm{M}_{\mathrm{B}}-$ наиболее вероятная магнитуда для наблюденного размера $\mathrm{L}_{\text {o }}$ (км) очага, оцениваемая с учетом соотношения:

$$
\mathrm{M}_{\mathrm{B}}=\lg \mathrm{L}_{\mathrm{o}}+5.5
$$

Анализ этих графиков (рис. 7) показал, что чем больше жесткость очага, тем меньше абсолютное значение наклона b графика повторяемости: для вялых очагов наклон $b=-1.35$ и выше, для жестких наклон $b$ уменьшается до -1.15 , а для супержестких - до -0.75 . Уменьшение абсолютной величины наклона и увеличение соотношения сильных и слабых очагов в сторону сильных, по-видимому, указывают на сокращение срока ожидания более сильного события, что и учитывалось при ОСР-97.

Большой разброс параметров (наклон, уровень активности) графиков повторяемости, полученных для локальных участков в зависимости от жесткости очагов, требует проведения детального анализа с учетом условий долговременного деформирования среды, учета влияния локальных неоднородностей и напряженно-деформированного состояния.

Супержесткие и жесткие очаги структурированны, они приурочены к узким зонам взаимодействия наиболее крупных структур, на которых происходит накопление напряжений. К этим структурам, как правило, могут быть приурочены более сильные землетрясения. Относительное изменение соотношения числа слабых и сильных событий в узких зонах разломов в сторону сильных определяет выполаживание регионального графика повторяемости в диапазоне больших магнитуд, в то время как вялые очаги рассеянны (диффузны) и приурочены к более мелким структурам с более низким сейсмическим потенциалом. Мелких структур значительно больше, чем крупных, и тем больше, чем меньше структура. Разделение очагов землетрясений с учетом их жесткости и выявленные тенденции изменения наклона $b$ в зависимости от жесткости очага дают основание для рассмотрения физической природы нелинейности региональных графиков повторяемости.

Использование результатов ОСР-97 для обоснования безопасности АС возможно, если доказано, что площадка не пересекается имеющимися в пределах домена (или сейсмотектонической провинции) структурами, включающими зацепы, формирующими зону подготовки очага будущего сильного сейсмического события. Обилие в локальной зоне вялых очагов с относительно небольшими магнитудами может указывать на относительное перемещение смежных блоков по ослабленной межблоковой границе без изменения объема, сопровождающегося релаксацией напряжений, общим возрастанием однородности массива и увеличением напряжений на более крупных неоднородностях. Жесткие очаги более активно влияют на процесс 


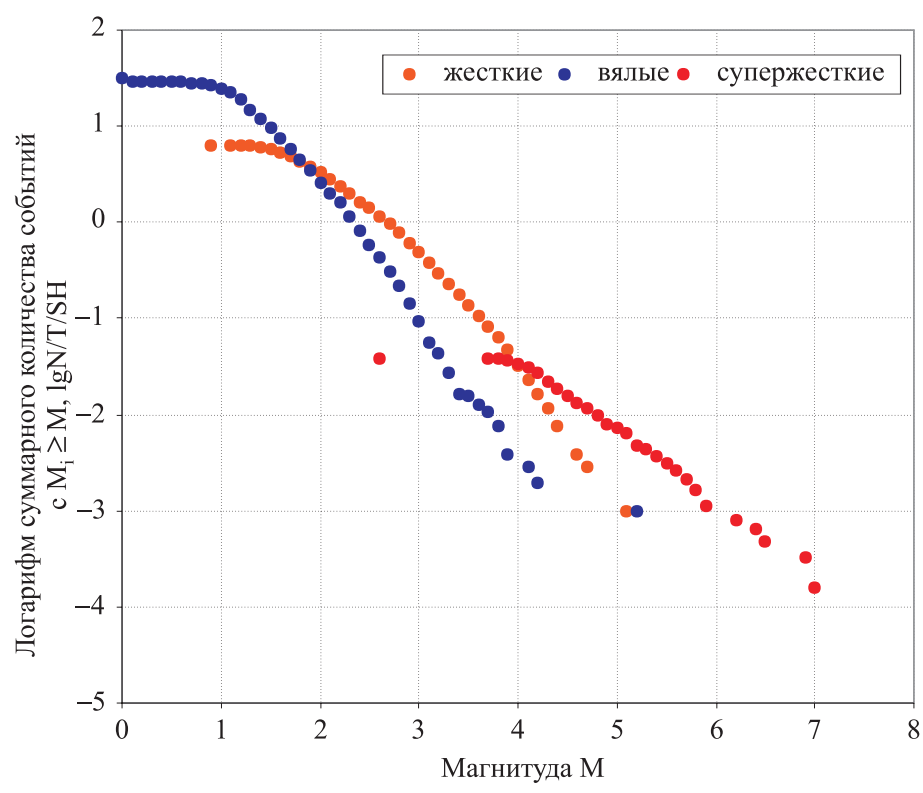

Рис. 7. Логарифм суммарного количества событий с $\mathrm{M}_{\mathrm{i}} \geq \mathrm{M}$, $\operatorname{lgN}$ для зоны Сан-Андреас, приведенного к 1 году и площади 1000 км² $^{2}$ для вялых (в), жестких (ж) и супержестких (сж) очагов. Графики повторяемости для представительных диапазонов магнитуд землетрясений с различной жесткостью очагов имеют: $\lg N_{\mathrm{B}}=3.0-1.35 \mathrm{M}_{\mathrm{B}}$, $\operatorname{lgN}_{ж}=3.0-1.15 \mathrm{M}_{ж}, \lg _{\mathrm{cж}}=1.49-0.73 \mathrm{M}_{\text {сж}}$, где $\mathrm{M}_{\mathrm{B}}-$ вялые очаги (при $\left.\mathrm{M}_{\mathrm{i}}<1.5 \lg \mathrm{L}_{\text {наб }}+4\right), \mathrm{M}_{\text {ж }}-$ жесткие очаги (1.5lgL $\left.\mathrm{L}_{\text {наб }}+4 \leq \mathrm{M}_{\mathrm{i}}<\lg \mathrm{L}_{\text {наб }}+5.5\right)$, $\mathrm{M}>\mathrm{M}_{\mathrm{B}}$ - супержесткие очаги $\left(\operatorname{lgL}_{\text {наб }}+5.5 \leq \mathrm{M}_{\mathrm{i}}\right), \mathrm{L}_{\text {наб }}$ - размер очага (км), принятый с учетом максимального горизонтального размера эллипса неопределенности.

Fig. 7. Logarithm of the total number of seismic events with $M_{i} \geq M$, $\operatorname{lgN}$, reduced to one year and an area of $1000 \mathrm{~km}^{2}$, for the San Andreas zone for non-stiff (в), stiff (ж) and super-stiff (сж) foci. For the representative sets of magnitudes with various stiffness of foci, recurrence curves are as follows: $\lg N_{\mathrm{B}}=3.0-1.35 \mathrm{M}_{\mathrm{B}}, \lg \mathrm{N}_{\mathcal{K}}=3.0-1.15 \mathrm{M}_{\text {}}, \lg \mathrm{N}_{\mathrm{CK}}=$ $=-0.73 \mathrm{M}_{\text {сж }}+1.49$ where $\mathrm{M}_{\mathrm{B}}-$ non-stiff foci (with $\mathrm{M}_{\mathrm{i}}<1.5 \lg \mathrm{L}_{\text {наб }}+4$ ), $\mathrm{M}_{\text {ж }}-$ stiff foci $\left(1.5 \lg \mathrm{L}_{\text {наб }}+4 \leq \mathrm{M}_{\mathrm{i}}<\lg \mathrm{L}_{\text {наб }}+5.5\right), \quad \mathrm{M}>\mathrm{M}_{\mathrm{B}}$ - super-stiff foci $\left(\lg \mathrm{L}_{\text {наб }}+5.5 \leq \mathrm{M}_{\mathrm{i}}\right), \mathrm{L}_{\text {наб }}$ - size of earthquake foci $(\mathrm{km})$ accepted with regard to maximum horizontal size of uncertainty ellipses.

накопления и перераспределения напряжений: чем сильнее зацепление, тем более высокие напряжения и деформации накапливаются и тем большая область среды подпадает под влияние зацепа и вовлекается в процесс подготовки сильного землетрясения. При достижении в области зацепа первого уровня предельных амплитуд смещений он может без разрушения включаться в область влияния зацепа второго уровня, имеющего больший размер предела амплитуд упругого деформирования. При этом амплитуда смещений зацепа первого уровня увеличивается, но уже на другом масштабном уровне, в рамках процесса более высокого порядка, и т.д. При этом наблюдаемые на графиках повторяемости горизонтальные полки соответствуют влиянию зацепов разных уровней. Чем больше уровень зацепа, тем для более высокого уровня магни- туд наблюдается полка на графике повторяемости, тем положе становится график повторяемости и шире диапазон магнитуд, соответствующий данному состоянию среды. Таким образом, положительное (в смысле подготовки сильного сейсмического события) развитие сейсмического процесса имеет тенденцию к увеличению масштабного уровня процесса, а предельные амплитуды деформаций захватывают все больший объем среды, что приводит к увеличению энергии потенциального землетрясения. Возможно, такая последовательность процесса стала причиной необычайно большого размера (порядка 280 км) очаговой зоны $\mathrm{R}_{0}$ землетрясения 11 марта 2011 г. на северо-востоке от острова Хонсю в Японии, в пределах которой максимальные ускорения были постоянны и превышали $1 \mathrm{~g}$. Обычно размер $\mathrm{R}_{\mathrm{o}}$ (км) очаговой зоны при землетрясении с $\mathrm{M=8.9}$ согласно соотношению [Аптикаев, 2001]: $\lg R_{0}=0.33 M_{s}-1.51$, не превышает 27-30 км, т.е. на порядок меньше. Это указывает на существование зацепов нескольких порядков.

Необходимость совершенствования методов оценки долговременной сейсмической опасности на основании каталогов землетрясений с использованием вероятностного подхода и гипотезы рассеянной сейсмичности требует проведения аналогичных оценок графиков повторяемости в другом районе. Проблема состоит в том, что традиционные каталоги не содержат информации, аналогичной информации, приведенной в уточненном каталоге по зоне Сан-Андреас. С учетом установленных особенностей ветвей графика повторяемости в области низких и больших магнитуд был выполнен анализ данных каталога землетрясений по району размещения АЭС Фукусима-1, участка проявления форшоковой и области проявления афтершоковой активности землетрясения 11 марта 2011 г. на северо-востоке от острова Хонсю в Японии. Рассмотрена зависимость параметров графика повторяемости от радиуса площади осреднения 300 и 150 км (рис. 8), и показано: график повторяемости для района $(\mathrm{R}<300$ км) имеет практически линейный вид во всем диапазоне магнитуд и наклон $\mathrm{b}=-1.09$; для района $(\mathrm{R} \leq 150$ км) график уже можно представить двумя ветвями: при $\mathrm{M}<6.3$ он более крутой $(\mathrm{b}=-1.18)$, а при $\mathrm{M}>6.3$ он более пологий $(\mathrm{b}=-0.81)$. Следует отметить, что имеет место слабовыраженная тенденция изменения значений ординат графика в диапазоне магнитуд от 6.4 до 6.9 (и для района $\mathrm{R}<300$ км).

Обращает на себя внимание сходство графиков повторяемости магнитуд супержестких очагов Калифорнии и относительно сильных землетрясений территории в радиусе 150 км (рис. 8), для которых при сопоставимой сейсмической активности для диапазона магнитуд от 4.0 до 7.0 и для диапазона магнитуд от 6.3 до 7.8 наклон равен -0.75 и -0.81 соответственно. Для кривой $(\mathrm{R}<150)$ на рис. 8 для диапазона магнитуд $\mathrm{M}>7.0$ нелинейность графика в области магнитуд больше 7.0 возрастает и величина наклона снижается 


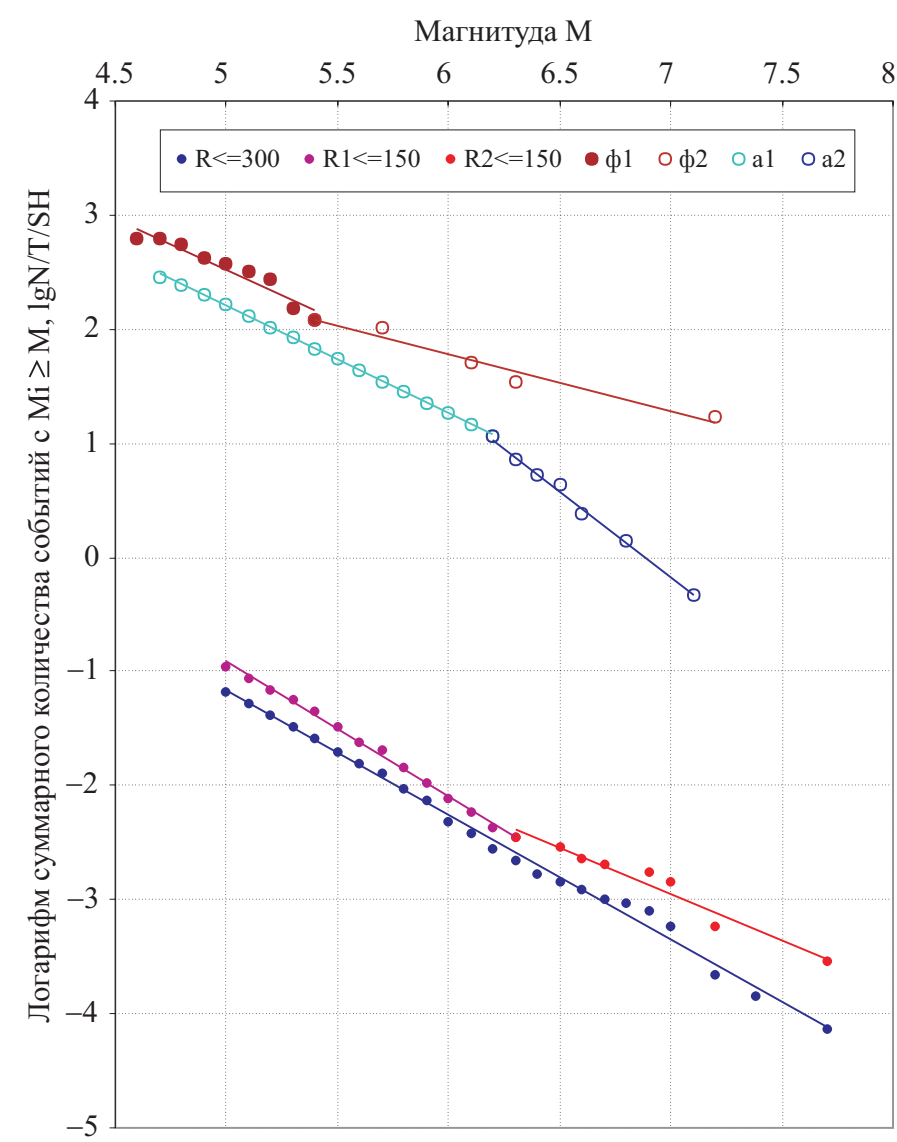

Рис. 8. Логарифм суммарного количества событий с $\mathrm{M}_{\mathrm{i}} \geq \mathrm{M}, \operatorname{lgN}$, приведенное к 1 году и 1000 км²$^{2}$ для района в радиусе $300(\mathrm{R}=300)$ и 150 км $(\mathrm{R}=150)$ от атомной станции Фукусима-1 за период 49 лет и форшоков (ф) и афтершоков (а) землетрясения 11 марта 2011 года с $\mathrm{M}_{\mathrm{w}}=8.9$. Графики повторяемости магнитуд района размещения АС Фукусима-1 имеют вид: $\lg N=4.3-1.1 \mathrm{M}$ для $\mathrm{R} \leq 300$ км, $\lg \mathrm{N}_{1}=5.0-1.2 \mathrm{M}$ для $\mathrm{R} \leq 150 \mathrm{kм}, \lg \mathrm{N}_{2}=2.7-0.8 \mathrm{M}$ для $\mathrm{R} \leq 150$ км; для форшоков землетрясения 11 марта 2011 года $\left(\mathrm{M}_{\mathrm{w}}=8.9\right)$ : $\lg \mathrm{N}_{\phi 1}=7.0$ $-0.9 \mathrm{M}_{\phi 1}, \lg \mathrm{N}_{\phi 2}=4.8-0.5 \mathrm{M}_{\phi 2}$; для афтершоков землетрясения 11 марта 2011 года $\left(\mathrm{M}_{\mathrm{w}}=8.9\right): \lg \mathrm{N}_{\mathrm{a} 1}=6.9-0.9 \mathrm{M}_{\mathrm{a} 1}, \lg \mathrm{N}_{\mathrm{a} 2}=10.4-1.5 \mathrm{M}_{\mathrm{a} 2}$.

Fig. 8. Logarithm of the total number of seismic events with $M_{i} \geq M$, $\operatorname{lgN}$, reduced to one year and an area of $1000 \mathrm{~km}^{2}$, for the region around Fukusima-1 Nuclear Station (R=300 km; R=150 km) for the period of 49 years and foreshocks (\$) and aftershocks (a) of 11 March 2011 earthquake with $\mathrm{M}_{\mathrm{w}}=8.9$. Magnitude recurrence curves for Fukusima-1 Nuclear Station site: $\operatorname{lgN}=4.3-1.1 \mathrm{M}$ for $\mathrm{R} \leq 300 \mathrm{~km}, \lg \mathrm{N}_{1}=5.0-1.2 \mathrm{M}$ for $\mathrm{R} \leq 150 \mathrm{~km}, \operatorname{lgN}_{2}=2.7-0.8 \mathrm{M}$ for $\mathrm{R} \leq 150 \mathrm{~km}$; for foreshocks of 11 March 2011 earthquake $\left(\mathrm{M}_{\mathrm{w}}=8.9\right): \quad \lg \mathrm{N}_{\phi 1}=7.0-0.9 \mathrm{M}_{\phi 1}, \quad \lg \mathrm{N}_{\phi 2}=$ $=4.8-0.5 \mathrm{M}_{\phi 2}$; for aftershocks of 11 March 2011 earthquake $\left(\mathrm{M}_{\mathrm{w}}=8.9\right)$ : $\operatorname{lgN}_{\mathrm{a} 1}=6.9-0.9 \mathrm{M}_{\mathrm{a} 1}, \lg \mathrm{N}_{\mathrm{a} 2}=10.4-1.5 \mathrm{M}_{\mathrm{a} 2}$.

до -0.5, что позволяет ожидать в данном районе землетрясения с $\mathrm{M}_{\mathrm{MP3}}$ до 9.1. Ограниченность числа событий, на основании которых сделан этот вывод, может быть серьезным основанием для критики полученного вывода. Однако проявление в рассматриваемой зоне землетрясения с $\mathrm{M}_{\mathrm{w}}=8.9$ и соответствие вероятностной оценки $\mathrm{M}_{\mathrm{MP}}$ детерминистским оценкам $\mathrm{M}_{\mathrm{MAX}}$ указывают на то, что установленные тенденции изменения параметров графиков повторяемости отражают реальные физические процессы, протекающие в области подготовки очага сильного землетрясения, отражающиеся в нелинейности графика повторяемости.

Для лучшего понимания параметров сейсмического процесса в области подготовки и проявления сильного сейсмического события были рассчитаны параметры графика повторяемости форшоковой последовательности (в период между первым форшоком (09.03.2011 г.) и главным событием) и параметры графика повторяемости афтершокового процесса (события в первые дни после главного события). Полученные результаты представлены на рис. 8. Из их сравнения с параметрами графиков повторяемости, соответствующих периоду подготовки главного события, следует, что график повторяемости форшоковой последовательности имеет значительно более высокий уровень (локальное повышение сейсмической активности в области относительно высоких магнитуд), который также характеризуется двумя ветвями:

$$
\begin{array}{ll}
\lg \mathrm{N}_{\phi 1}=7.2-0.9 \mathrm{M}_{\phi 1} & (\mathrm{M}<5.4), \\
\lg \mathrm{N}_{\phi 2}=4.95-0.5 \mathrm{M}_{\phi 2} \quad(\mathrm{M}>5.4) .
\end{array}
$$

На графике повторяемости магнитуд форшоковой последовательности тенденция уменьшения наклона b до -0.54 (соотношение (14)), установленная для диапазона магнитуд $\mathrm{M}>7.0$, распространилась на события до $\mathrm{M}=5.4$, а сама величина b снизилась до -0.5. При этом период ожидания прогнозируемого события с $\mathrm{M}_{\text {мах }}=8.3$, согласно соотношению (14), снизился до 1.86 года, а с учетом соотношения (15) - до 0.16 года. Установленные тенденции изменения формы, активности и наклона b кумулятивных графиков повторяемости магнитуд, по-видимому, могут быть использованы для локации мест наиболее вероятного проявления сильных землетрясений и краткосрочного прогноза периода ожидания сильного сейсмического события. При этом нельзя исключать из рассмотрения, что не менее эффективным может оказаться простое соотношение количества жестких и вялых очагов.

График повторяемости магнитуд афтершоковой последовательности за первые одиннадцать дней имеет традиционный вид, но отличается более высоким уровнем активности (см. рис. 8):

$$
\lg \mathrm{N}_{\mathrm{a \phi}}=7.1-1.0 \mathrm{M}_{\mathrm{a \phi}} \quad(4.7<\mathrm{M}<7.1) .
$$

Наклон b этого графика практически совпадает со среднемировым значением, установленным для района $(\mathrm{R}<300$ км), и отражает процесс релаксации напряжений, характерный для Земли в целом, но на гораздо более высоком уровне сейсмической активности. При этом увеличение периода ожидания событий с $\mathrm{M}_{\text {мах }}=8.3$ с 0.16-1.86 года (согласно результатам анализа форшоковой последовательности) до 11 лет одно- 
значно указывает на тенденцию релаксации напряжений и их постепенное возвращение на начальный уровень.

Особенностью графика повторяемости афтершоков, как и форшоков или сейсмических событий в области подготовки сильных событий, является также наличие двух ветвей, но наклон этих ветвей является обратным. Если при подготовке сильных сейсмических событий происходит выполаживание графика повторяемости в области сильных событий и изменение соотношения числа сильных и слабых событий в пользу сильных, то при афтершоках, наоборот, в области сильных событий абсолютное значение наклона b существенно превышает эту величину для диапазона более слабых событий:

$$
\begin{array}{ll}
\lg \mathrm{N}_{\mathrm{a} 1}=6.9-0.9 \mathrm{M}_{\mathrm{a} 1} & (4.7<\mathrm{M}<6.2), \\
\lg _{\mathrm{a} 2}=10.4-1.5 \mathrm{M}_{\mathrm{a} 2} & (6.2<\mathrm{M}<7.1) .
\end{array}
$$

После сильного землетрясения развитие сейсмического процесса изменяется: соотношение числа слабых и сильных событий смещается в пользу слабых, при этом активность и наклон графика повторяемости в зоне влияния очага сильного землетрясения постепенно уменьшаются до величин, характерных для графика повторяемости рассматриваемого района.

Отсутствие в каталогах землетрясений Японии информации, необходимой для разделения очагов землетрясений с учетом их жесткости, ограничивает возможности более детального анализа сейсмического процесса. Тем не менее раздельный анализ графиков повторяемости с учетом особенностей их поведения в области относительно слабых и относительно сильных сейсмических событий подтверждает основные закономерности, установленные для зоны Сан-Андреас в Калифорнии, и общий характер подготовки и реализации сильных сейсмических событий в разных районах.

При объединении нескольких зацепов в единую структуру более высокого порядка соотношение числа слабых и сильных землетрясений изменяется в пользу сильных, так как относительно слабые (вялые) очаги уже успели реализоваться. График повторяемости становится более пологим, при этом в пределах области влияния системы зацепов могут появляться локальные области затишья за счет снижения числа вялых очагов.

Полученный результат полезен при рассмотрении физической природы нелинейности региональных графиков повторяемости, позволяет посмотреть на проблему «затишья» с позиции наличия в земной коре условного кристалла - зацепа первого, второго и/или более высокого уровня, когда основная масса вялых очагов уже сработала и идет процесс наращивания критической массы. В этих условиях главному событию в пределах зацепа, накопившего максимальную амплитуду смещений, превышающую предельную, могут предшествовать сильные жесткие форшоки, график повторяемости которых может иметь высокую активность и малый наклон b.

\section{2. ПРОСТРАНСТВЕННОЕ РАСПРЕДЕЛЕНИЕ ЖЕСТКИХ И ВЯЛЫХ ОЧАГОВ}

Специфические особенности пространственного проявления землетрясений в зоне локальной структуры разлома Калаверс, входящего в зону разлома СанАндреас, детально рассмотрены в работе [Kocharyan et al., 2010], в которой показано, что увеличение точности результатов сейсмологических исследований серьезно расширяет возможности использования уточненных каталогов сейсмических событий для изучения структурной приуроченности очагов землетрясений. В этой работе была установлена четкая структурная приуроченность очагов землетрясений к узким локальным зонам влияния разломов. Например, более 75 \% эпицентров локализованы в узкой зоне разлома Калаверс шириной $\mathrm{W}=110 \pm 10$ м и контролируют положение активной тектонической структуры; остальные 25 \% более слабых землетрясений определяют рассеянную (диффузную) сейсмичность, которая также приурочена к нарушениям, но меньшего порядка, не выявленным до настоящего времени. При этом отмечено более значительное рассеяние (отклонение) от оси зоны максимальной концентрации очагов слабых событий по сравнению с более сильными очагами.

Для дальнейшего развития результатов работы [Kocharyan et al., 2010] выполнен анализ пространственного распределения жестких и вялых очагов на участке разлома Калаверс, который показал, что к узкой зоне разлома приурочены как жесткие, так и вялые очаги (рис. 9). Проявление жестких и вялых очагов в узкой зоне разлома указывает на реализацию в зоне разлома землетрясений с различным характером разрушения среды. Эти различия обусловлены существованием в зоне разлома мелких неоднородностей, которые различно (образуя сдвиг, отрыв, скол) реагируют на воздействие долговременных региональных и локальных тектонических воздействий. На зацепах в зоне разлома напряжения и деформации накапливаются, постепенно в этот процесс вовлекается все большая и большая часть территории в зоне влияния зацепа, образуя систему зацепов разного порядка (уровня). Временами этот процесс прерывается разрушением того или иного зацепа, проявляющимся в виде жесткого очага и серии жестких и вялых очагов меньших или сравнимых порядков в зоне влияния зацепа, но затем он продолжается в глобальном направлении - подготовке сильного сейсмического события. На неоднородностях, где нет предпосылок для формирования зацепа, происходит релаксация локальных напряжений путем проскальзывания взаимодействующих блоков по межблоковой ослабленной границе (сдвиг) и проявления вялого очага. При этом нельзя исключать и образования в зоне интенсивного сжатия трещин отрыва, 


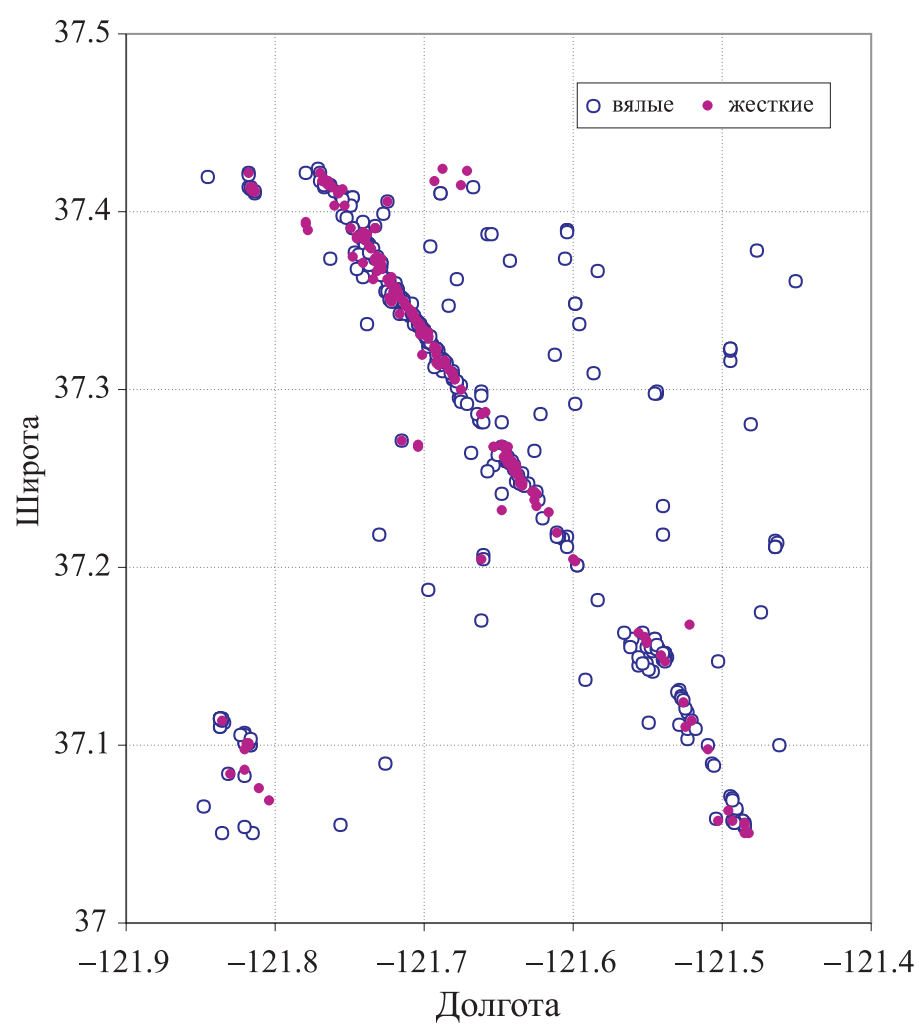

Рис. 9. Фрагмент распределения жестких и вялых очагов локальной зоны разлома Калаверс, входящего в систему зоны разлома СанАндреас, отражающий проявление структурированной и рассеянной (диффузной) сейсмичности.

Fig. 9. Fragment of distribution of stiff and non-stiff foci of the local zone of the Calaveral fault in the San Andreas fault system. It illustrates structured and dissipated / diffuse seismicity.

простирание которых совпадает с направлением действия тектонических сил. Характер проявления трещин сдвига и отрыва, по-видимому, также похож на характер проявления импульсов релаксации. В данном случае под характером проявления понимаются особенности спектрального состава колебаний. Импульсы релаксации, как и вялые очаги землетрясений, имеют одну характерную частоту [Кочарян, Спивак, 2003; Раутиан, 1988], но могут различаться интенсивностью и частотным составом. Жесткие очаги должны иметь как минимум две характерных частоты [Касахара, 1985; Раутиан, 1988]: первую частоту можно оценить на основании размера зацепа и скорости его разрушения, вторая частота определяется максимальной амплитудой поднятия территории при действии зацепа и массовой скоростью движения горных пород после разрушения зацепа.

Если жесткие очаги преимущественно приурочены к узким зонам проявления максимальных деформаций и напряжений, то вялые очаги не только приурочены к зоне разлома, но и относительно равномерно распределены в пределах окружающей его территории, во- влекаемой в общий сейсмический процесс подготовки сильного сейсмического события. Реализация вялых очагов приводит к увеличению однородности массива и повышению напряжений и деформаций на крупных неоднородностях до упругого предела при одноосном сжатии и выше в зонах зацепов. В зонах относительно крупных неоднородностей, являющихся структурными границами однопорядковых тектонических блоков, могут возникать зацепы различных порядков более низкого уровня, на которых деформации могут существенно превышать упругий предел. В таких случаях происходит включение зацепов первого уровня в зацепы второго и более высокого уровней, что изменяет условия подвижности блоков.

Кроме того, одновременное проявление в узкой зоне разлома жестких и вялых очагов может быть обусловлено наличием участков повышенной и пониженной прочности, а также влиянием неоднородности локального напряженно-деформированного состояния среды в зоне разлома. Чередование участков локального сжатия или растяжения способствует формированию зацепов, разрушение которых может сопровождаться быстрыми срывами или медленным проскальзыванием по ослабленным межблоковым границам.

\section{7. ОБСУЖДЕНИЕ РЕЗУЛЬТАТОВ РАБОТЫ}

Долговременные ряды сейсмологических наблюдений в пределах домена (сейсмотектонической провинции) позволяют оценивать среднюю долговременную сейсмическую опасность и контролировать стабильность параметров сейсмического режима во времени. Учет соотношения числа жестких и вялых очагов позволяет предполагать наличие в рассматриваемом районе областей подготовки сильных сейсмических событий на основании локального повышения сейсмической активности и уменьшения абсолютных значений наклона b, что проявляется в виде наличия полки (или полок) на графике повторяемости. «Сканирование» территории района радиусом 100, 30, 10 и 3 км позволяет локализовать места зацепов (участков подготовки сильных сейсмических событий) разного порядка, для которых наиболее выражены тенденции изменения соотношения числа слабых и сильных событий в пользу сильных.

Если долговременные графики повторяемости Гутенберга-Рихтера позволяют прогнозировать долговременную сейсмическую опасность, необходимую для принятия проектных решений, то анализ графика повторяемости форшоковой последовательности позволяет оценивать время ожидания сильного события и использовать эту информацию для принятия решения об организационных и технических мероприятиях по обеспечению безопасности при главном событии.

Анализ графика повторяемости афтершоковой последовательности не противоречит закону Омори, от- 
ражает процесс релаксации напряжений в очаговой зоне сильного землетрясения, который проявляется в постепенном увеличении абсолютного значения наклона, при этом на начальной стадии наклон правой ветви (область больших магнитуд) может быть больше наклона левой ветви. После релаксации максимальных напряжений соотношение наклонов правой и левой ветви может неоднократно меняться в зависимости от количества и порядка зацепов, включенных в процесс накопления деформаций в период подготовки главного события. По мере приближения к естественному фону график повторяемости афтершоков стремится к линейному графику повторяемости Гутенберга-Рихтера с наклоном $b=-1.0$. При этом блочно-иерархическое строение земной коры и структурная соподчиненность тектонических блоков различных порядков определяют справедливость закона Бата, устанавливающего разницу магнитуд главного события и наиболее сильного афтершока. Эта разница физически определяется меньшим уровнем деформаций и напряжений и меньшим размером зоны взаимодействия тектонических блоков, в которой проявляется афтершок. Для более детального изучения сейсмического процесса представляется целесообразным оценивать соотношение жестких и вялых очагов и их структурную приуроченность в процессе подготовки землетрясений, форшоковой активизации и процессе афтершоковой последовательности, что дает основание более надежно судить о характере развития сейсмического процесса во времени и пространстве.

Задачи сейсмологического мониторинга стабильности параметров сейсмического режима в пространстве и во времени на участках размещения АС и других ответственных объектов должны включать:

- определение координат, магнитуды и параметров очага (размер и амплитуда подвижки) для установления его типа (жесткий, вялый), структурной приуроченности,

- выявление мест подготовки сильных сейсмических событий и оценку их максимальной магнитуды, ее повторяемости, а также своевременную подготовку рекомендаций для обеспечения безопасности АС в период сооружения, эксплуатации и вывода АС из эксплуатации.

При этом необходимо особое внимание уделять анализу природы очагов землетрясений различных типов. На основе взглядов С.Н. Тагильцева (http:/geomaster.ucoz.ru) можно принять, что трем видам трещин: сдвигу, отрыву и сколу - могут соответствовать вялые и жесткие очаги. Согласно работе [Кочарян, Спивак, 2003], трещины сдвига в горных породах представляют собой не что иное, как плоскости относительного смещения тектонических блоков по ослабленным межблоковым границам, которые сопровождаются образованием импульсов релаксации (микроземлетрясений). Образование трещин сдвига связано со стремлением тектонических блоков различ- ного порядка выйти из-под действия тектонических сил без изменения объема путем пластического скольжения по ослабленной межблоковой границе. Особенностью механизма образования трещин сдвига является соотношение их размера и амплитуды подвижки. Как правило, в рассматриваемом случае размеру подвижки соответствует ее минимальная амплитуда, при этом предельные деформации в очагах импульсов релаксации согласно результатам регистрации импульсов релаксации не превышают $3 \cdot 10^{-7}$, что позволяет относить такие события к вялым очагам.

Трещины отрыва, как правило, начинают формироваться, когда в результате сдвигов по межблоковым границам низких порядков породы упрочняются и входят в структуру квазиоднородного тектонического блока более высокого порядка. Процесс постепенного перехода от стадии пластических деформаций на структурах более низкого порядка к упругому деформированию более крупного блока сопровождается стадией хрупкого разрушения мелких неоднородностей. Согласно С.Н. Тагильцеву, на этой стадии разрядка напряжений происходит более резко в виде «щелчков», которые отражают образование микроразрывов, представляющих собой трещины отрыва. Трещины отрыва располагаются параллельно оси действия главного максимального напряжения $\sigma 1$, угол альфа для них равен нулю. На практике наложение локальных напряжений, связанных с параметрами зон зацепов на локальных структурах различного порядка, на региональное поле напряжений затрудняет установление типа подвижки в очаге, для этого как раз и нужны детальные сейсмологические наблюдения, на что справедливо указано в работе [Kocharyan et al., 2010]. При этом следует отметить, что, согласно результатам анализа параметров сейсмодислокаций, установлено, что предел упругого деформирования и хрупкого разрушения в очаге при всестороннем сжатии в условиях дискретно-иерархической блочной среды равен $10^{-6}$ [Бугаев, Спивак, 2002].

Формирование трещин скола, по С.Н. Тагильцеву, происходит под действием внешних тектонических сил в зоне зацепа квазиоднородных тектонических блоков более крупного порядка путем вовлечения трещин сдвига и трещин отрыва в единый тектонический процесс, что в конечном итоге приводит к формированию единой поверхности трещины скола. Трещина скола имеет сложное строение и представляет собой ступенчатую поверхность, состоящую из микротрещин отрыва и микротрещин сдвига. Трещина скола может проявляться в зонах зацепов различных порядков. Разрушение зацепа сопровождается проявлением жестких очагов, для которых характерно превышение предела упругого деформирования и хрупкого разрушения при одноосной деформации сжатия, равной $3 \cdot 10^{-5}$ [Бугаев, Спивак, 2002], а также образованием волны разгрузки в зоне влияния зацепа, обусловленной обрушением огромной массы пород, приподнятой в 
результате длительного действия сжимающих тектонических напряжений. С учетом дискретноиерархического характера среды в зоне влияния зацепа, максимальный потенциал сейсмических событий (афтершоков) в зоне разгрузки не может превышать максимальный потенциал главного события (соблюдение закона Бата). С учетом того, что мелких неоднородностей значительно больше, чем крупных, соблюдается закон Омори. Чем больше порядок зацепа, тем больший объем среды вовлекается в процесс накопления энергии и тем бо́льшие предельные деформации могут быть реализованы. Область влияния зацепа может распадаться на самостоятельные структурные блоки различных порядков со своими законами релаксации напряжений и соотношениями сильных и слабых событий. В области релаксации напряжений должны преобладать вялые очаги. При подготовке сильного сейсмического события постепенно соотношение слабых и сильных событий должно меняться в пользу сильных событий (см. рис. 4б). Это было отмечено при анализе каталогов землетрясений в районе AC Фукусима-1 и землетрясения 11 марта 2011 г. в районе острова Хонсю в Японии, где в результате длительного действия тектонических сил сформировалась система зацепов различного порядка, зона влияния которых охватила почти всю микроплиту, включающую остров Хонсю.

\section{8. ЗАКЛЮЧЕНИЕ}

Принятое соответствие максимального горизонтального размера эллипса неопределенности и размера очага показало актуальность включения в изучение сейсмического процесса дополнительной информации, позволяющей разделять сейсмические события на жесткие и вялые очаги, установить физическую природу нелинейности графиков повторяемости магнитуд и более обоснованно выполнять оценку сейсмической опасности.

Анализ результатов детального изучения потенциальных очаговых зон указывает на актуальность увеличения детальности геолого-геофизических исследований и повышения «чувствительности» сейсмологических исследований для увеличения точности определения положения сейсмических источников и расширения задач локального сейсмологического мониторинга АС. В каталоги землетрясений рекомендуется, наряду с традиционными параметрами, дополнительно включать размеры разрывов трещины и амплитуду подвижки в очаге, а также другие параметры, обычно фиксируемые в каталогах локальных и местных землетрясений детальных сейсмологических мониторинговых наблюдений на участках размещения АС и других ответственных объектов дополнительной информации.

Детальное изучение условий проявления землетря- сения, раздельная оценка параметров графиков повторяемости магнитуд жестких и вялых очагов позволят более достоверно и надежно обосновывать стабильность параметров проектного и максимального расчетного землетрясения, включенных в проектные основы, и своевременно готовить рекомендации по обеспечению безопасности в случае негативного изменения сейсмических условий.

С учетом результатов впервые проведенных К. Моги экспериментальных исследований зависимости хрупкого и квазихрупкого разрушения и пластического течения от величин напряжений $[\mathrm{Mogi}, 1966]$ и работы [Ребецкий, 2006] представляется возможным заключить, что механизм разрушения в очаге, а также уровень и наклон графиков повторяемости магнитуд зависят от уровня и характера обжимающих напряжений. Хрупкое разрушение происходит при относительно низком всестороннем давлении и низких напряжениях, о чем свидетельствуют результаты регистрации импульсов релаксации в пределах слабоактивных территорий и наличие вялых очагов, при этом наклон графика повторяемости может быть бо́льшим по сравнению со среднемировым значением. При высоком уровне напряжений и высоком давлении хрупкое разрушение зацепа (спайки) в энергонасыщенной среде дополняется локализованным пластическим течением; чем выше эффективное всестороннее давление, тем бо́льшая часть сил затрачивается на преодоление сил трения и больше предельные деформации в очагах, при этом величина наклона понижается, а уровень сейсмической активности возрастает. В предельном случае в зонах интенсивной раздробленности происходит пластическое течение (криповое разрушение), сопровождающееся микрохрупкими деформациями на локальных неоднородностях, размер которых не превышает первые десятки - сотни метров (например, в районах с умеренной и слабой сейсмичностью 300 м). В этих условиях наклон графика повторяемости может сильно возрастать, как и сейсмическая активность микроземлетрясенний (вялых очагов). В то же время на локальных неоднородностях, препятствующих относительно свободному перемещению межблоковых границ, будут возникать зацепы (спайки), которые являются предпосылками для возникновения жестких очагов со всеми вытекающими отсюда последствиями - постепенным снижением угла наклона и перераспределением соотношения числа сильных и слабых событий в пользу сильных.

Увеличение количества параметров, включаемых в каталоги землетрясений, расширит возможности изучения пространственных и временных закономерностей изменения сейсмического процесса за счет раздельного рассмотрения жестких и вялых очагов, характеризующих различные условия формирования и проявления землетрясений на локальном, региональном и глобальном уровне. 


\section{9. ЛИТЕРАТУРА}

Аптикаев Ф.Ф. Сильные сейсмические движения грунта при землетрясениях (сейсмические воздействия): Автореф. дис. ... докт. физ.-мат. наук. М., 2001. 47 с.

Арефьев С.С. Эпицентральные сейсмологические исследования. М.: ИКЦ «Академкнига», 2003. 375 с.

Болт Б.А. Землетрясения. Общедоступный очерк. М.: Мир, 1984. 356 c.

Бугаев Е.Г., Спивак А.А. Оценка эффективных деформационных и прочностных характеристик среды в очагах землетрясений // Нестационарные процессы в верхних и нижних оболочках Земли (геофизика сильных возмущений). М.: ИДГ РАН, 2002. C. 77-85.

Бугаев Е.Г., Спунгин В.Г. Комплексное изучение условий возникновения очагов землетрясений // Сборник материалов Международной научной конференции «Уроки и следствия сильных землетрясений (к 80-летию разрушительных землетрясений в Крыму)», Ялта, 25-28 сентября 2007 г. Симферополь: Институт геофизики НАНУ, Крымский экспертный совет, 2007. С. 162164.

Ваков А.А. Геометрические параметры и магнитуда очагов землетрясений при различных типах подвижек // Вопросы инженерной сейсмологии. Вып. 33 (Инженерно-сейсмологические исследования для районирования сейсмической опасности). М.: Наука, 1992. С. 40-53.

Востриков В.А. Связь параметров графика повторяемости, сейсмического течения и очага землетрясения // Труды Геологического института РАН. Вып. 482. М.: Наука, 1994.

Гейликман М.Б., Писаренко В.Ф. О самоподобии в геофизических явлениях // Дискретные свойства геофизической среды / Отв. ред. М.А. Садовский. М.: Наука, 1989. С. 109-131.

Грачев А.Ф. О природе Нью Мадридской зоны высокой сейсмической активности на североамериканской платформе // Физика Земли. 1994. № 12. С. 12-23.

Добровольский И.П. Механика подготовки тектонического землетрясения. М.: ИФЗ АН СССР, 1984. 189 с.

Кайе А., Трикар Ж. Проблемы классификации геоморфологических явлений // Вопросы климатической и структурной геоморфологии. М.: Иностранная литература, 1959. С. 32-66.

Касахара К. Механика землетрясений. М.: Мир, 1985. 264 с.

Комплексные инженерно-геофизические исследования при строительстве гидротехнических сооружений / Под ред. А.И. Савича, Б.Д. Куюнджича. М.: Недра, 1990. 463 с.

Кочарян Г.Г., Спивак А.А. Динамика деформирования блочных массивов горных пород. М.: ИКЦ «Академкнига», 2003. 423 с.

Никонов А.А. Голоценовые и современные движения земной коры: геолого-геоморфологические и сейсмотектонические вопросы. М.: Наука, 1977. 240 с.

Никонов А.А. Реконструкция основных параметров древних сильных землетрясений Средней Азии на основе палеосейсмологического метода // Вопросы инженерной сейсмологии. Вып. 28 (Сильные землетрясения и сейсмические воздействия). М.: Наука, 1987. С. 72-91.

Пиотровский М.В. Использование морфометрии для изучения рельефа и строения Земли // Земля во Вселенной. М., 1964. С. 278-297.

Прозоров А., Хадсон Д. Соотношение поверхностных и объемных волн в различных регионах и в цепочках взаимосвязанных землетрясений // Вычислительная сейсмология. Вып. 7 (Машинный анализ цифровых сейсмических данных). М.: Наука, 1974. C. $65-84$.

Пустовитенко Б.Г., Пантелеева Т.А. Спектральные и очаговые параметры землетрясений Крыма. Киев: Наукова Думка, 1990. 252 c.

Раутиан Т.Г. Определение параметров субочагов землетрясений и их интерпретация // Вопросы инженерной сейсмологии. Вып. 29. М.: Наука, 1988. С. 21-29.

Ребецкий Ю.Л. Проблемы прогноза землетрясений - новая модель очага землетрясений // Активные геологические и геофизические процессы в литосфере. Методы, средства и результаты изучения: Материалы международной конференции. Воронеж, 2006. T. 2. C. $105-110$.

Садовский М.А. О естественной кусковатости горных пород // Доклады АН СССР. 1979. Т. 247. № 4. С. 829-831.

Соболев Г.А., Пономарев А.В. Физика землетрясений и предвестники. М.: Наука, 2003. 270 с.

Стром А.Л. Сопоставление параметров современных и палеосейсмодислокаций // Физика Земли. 1993. № 9. С. 38-42.

Тяпкин К.Ф. Физика Земли. Киев: Выща школа, 1988. 310 с.

Уломов В.И. Физическая модель очаговой области Газлийских землетрясений 8 апреля и 17 мая 1976 года // Сейсмологические исследования в Узбекистане. Ташкент: Издательство «ФАН» Узбекской ССР, 1979. С. 53-63.

Уломов В.И. Региональные структуры сейсмичности // Современная динамика литосферы континентов. Подвижные пояса / Под ред. Н.А. Логачева, В.С. Хромовских. М.: Недра, 1995. С. 401419.

Уломов В.И., Шумилина Л.С. Комплект карт общего сейсмического районирования территории Российской Федерации - ОСР-97. Масштаб 1:8000000. Объяснительная записка и список городов и населенных пунктов, расположенных в сейсмоопасных районах. М., 1999. 57 с.

Хромовских В.С. Сравнительная сейсмогеология активизированных в кайнозое древних платформ и молодых складчатых областей Евроазиатского континента // Основные проблемы сейсмотектоники. М.: Наука, 1986. С. 178-182.

Хромовских В.С. Сейсмогенные деформации земной коры в эпицентральных и плейстосейстовых зонах сильных землетрясений // Современная динамика литосферы континентов. Подвижные пояса / Под ред. Н.А. Логачева, В.С. Хромовских. М.: Недра, 1995. С. 440-503.

Шебалин Н.В. Сильные землетрясения. Избранные труды. М.: Издво Академии горных наук, 1997. 542 с.

Штейнберг В.В., Пономарева О.Н. О размерах сильных землетрясений // Вопросы инженерной сейсмологии. Вып. 28 (Сильные землетрясения и сейсмические воздействия). М.: Наука, 1987. C. 63-72.

Benedik A.L., Ivanov A.V., Kocharyan G.G. Design of structural models of sections of the earth's crust at different hierarchical levels // Journal of Mining Science. 1995. V. 31. № 5. P. 345-354. doi:10.1007/ BF0204 6630.

Bonilla M.G. Surface faulting and related effects // Earthquake Engineering / Ed. R.L. Wiegel. Englewood Cliffs, N. J.: Prentice-Hall, 1970. P. 47-74.

Bonilla M.G., Mark R.K., Liekaemper J.J. Statistical relations among earthquake magnitude, rupture length, surface fault displacement // Bulletin of the Seismological Society of America. 1984. V. 74. № 6. P. 2379-2412.

Chinnery M.A. The deformation of the ground around surface faults. // Bulletin of the Seismological Society of America. 1961. V. 51. № 3. P. 22-41.

Chiu J. A high resolution PANDA experiment in the central New Madrid seismic zone // Geological Society of America Abstracts. 1990. V. 22. P. A17.

Gomberg J. Tectonic deformation in the New Madrid seismic zone: inferences from map view and cross-sectional boundary element models // Journal of Geophysical Research. 1993. V. 98. № B4. P. 6639-6664. doi:10.1029/92JB02857.

Iida K.J. Earthquake energy and earthquake fault // Journal of Earth Sciences, Nagoya University. 1959. V. 7. P. 98-107.

Iida K.J. Earthquake magnitude, earthquake fault and source dimensions // Journal of Earth Sciences, Nagoya University. 1965. V. 13. № 1. P. 15-32.

Kocharyan G.G., Kishkina S.B., Ostapchuk A.A. Seismic picture of a fault zone. What can be gained from the analysis of fine patterns of spatial distribution of weak earthquake centers? // Geodynamics \& Tectonophysics. 2010. V. 1. № 4. P. 419-440.

Mandelbrot B. The fractal geometry of nature. San Francisco: W.H. 
Freeman and Co., 1982. 460 p.

Matsuda T. Magnitude and recurrence interval of earthquake from a fault // Journal of the Geological Society of Japan. 1975. V. 28. № 11. P. 269-283.

Mogi K. Pressure dependence of rock strength and transition from brittle fracture to ductile flow // Bulletin of the Earthquake Research Institute. 1966. V. 44. № 1. P. 215-232.

Strom A.L., Nikonov A.A. Relations between the Seismogenic fault pa- rameters and earthquake magnitude // Izvestiya. Physics of the Solid Earth. 1997. V. 33. № 12. P. 1011-1022.

Tocher D. Earthquake energy and ground breakage // Bulletin of the Seismological Society of America. 1958. V. 48. № 2. P. 147-153.

Waldhauser F., Schaff D.P. Large-scale relocation of two decades of Northern California seismicity using cross-correlation and doubledifference methods // Journal of Geophysical Research. 2008. V. 113. B08311. doi:10.1029/2007JB005479.

Бугаев Евгений Геннадьевич, докт. технических наук, с.н.с., начальник отдела устойчивости к внешним воздействиям Научно-технический центр по ядерной и радиационной безопасности 107140, Москва, ул. Малая Красносельская, 2/8, строение 5, Россия Тел.: 8(499)2640648 (служебный), факс: +7(499)2642859; $\$ e-mail: bugaev-eg@yandex.ru

Bugaev, Evgeny G., Doctor of Technical Sciences, Senior Researcher, Head of Stability against External Impacts Section Scientific and Engineering Centre for Nuclear and Radiation Safety, Federal Agency 107140, Moscow, Malaya Krasnoselskaya Street, 2/8, Bld. 5, Russia Tel.: 8(499)2640648 (office), Fax: +7(499)2642859; $₫$ e-mail: bugaev-eg@yandex.ru 